\title{
Role of structures on thermal conductivity in thermoelectric materials
}

\author{
C. Godart ${ }^{1}$, A.P. Gonçalves ${ }^{2}$, E.B. Lopes ${ }^{2}$, B. Villeroy ${ }^{1}$ \\ ${ }^{3}$ CNRS, ICMPE, CMTR, 2/8 rue Henri Dunant, 94320 Thiais, France \\ ${ }^{2}$ Dep. Química, Instituto Tecnológico e Nuclear/CFMC-UL, P-2686-953 Sacavém, Portugal
}

Role of structures on thermal conductivity in thermoelectric materials .......... 1

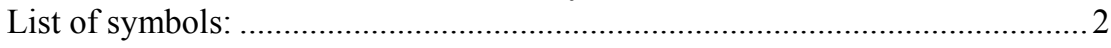

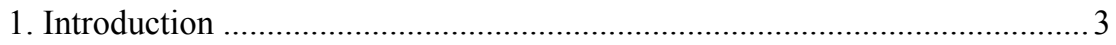

2. The thermoelectric effects ................................................................. 4

3. Efficiencies, Figure of merit .................................................................... 4

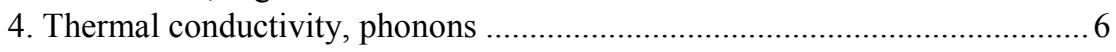

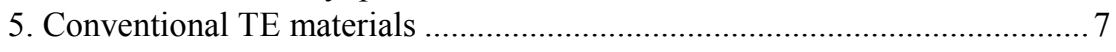

6. Recent bulk TE materials............................................................................ 8

6.1. ADP (Atomic Displacement Parameter) ......................................... 8

6.2. Cage like TE materials ............................................................... 9

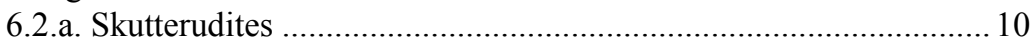

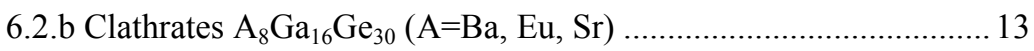

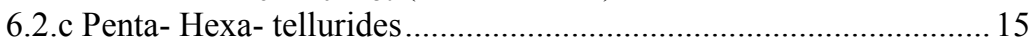

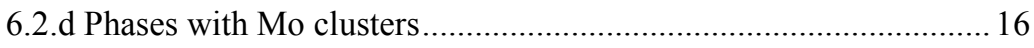

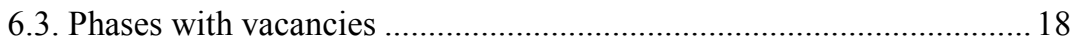

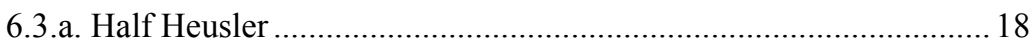

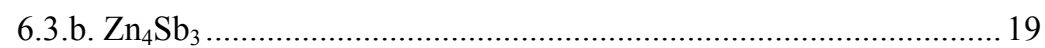

6.4. Complex solid solutions derived from conventional materials ............ 20

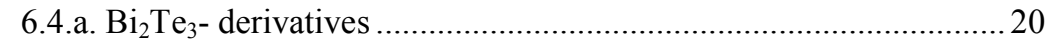

6.4.b derivatives from $\mathrm{PbTe}$ and TAGS.............................................. 21

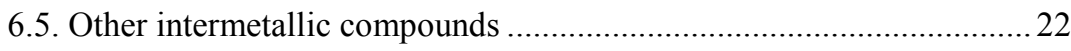

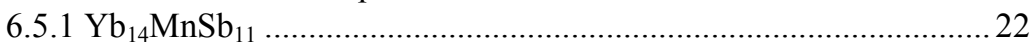

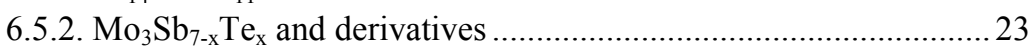

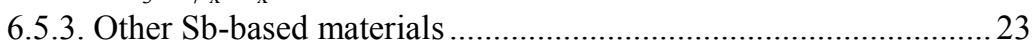

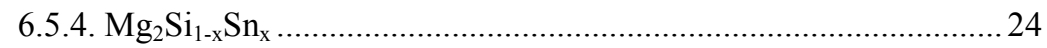

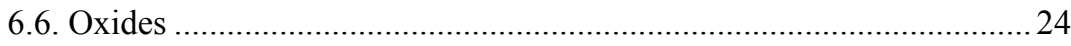

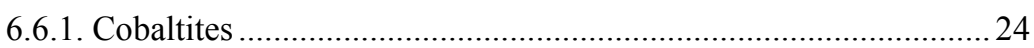

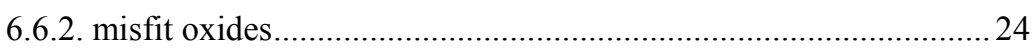

6.6.3. other oxides............................................................................ 25

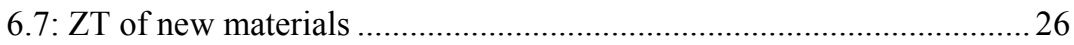

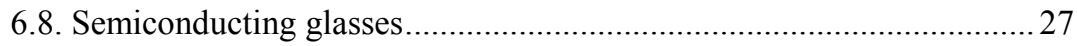

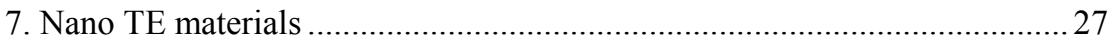

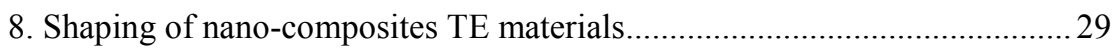

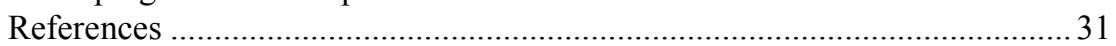




\title{
List of symbols:
}

\author{
$\alpha$ : Seebeck coefficient \\ $\lambda$ : thermal conductivity \\ $\lambda_{\mathrm{e}}$ : electronic part of the thermal conductivity \\ $\lambda_{\mathrm{L}}$ : phonon (lattice) part of the thermal conductivity \\ $\mu$ : mobility \\ $\rho$ : electrical resistivity \\ $\sigma$ : electrical conductivity \\ $\tau$ : Thomson coefficient \\ $\Pi$ : Peltier coefficient \\ ADP: Atomic Displacement Parameter \\ I: intensity \\ PGEC: Phonon Glass Electron Crystal \\ q: charge of a carrier \\ Q: heat quantity \\ S: entropy \\ TE: thermoelectric \\ $\mathrm{V}$ : potential \\ VEC: Valence Electron Concentration \\ ZT: Figure of merit
}

\begin{abstract}
The figure of merit $\mathrm{ZT}=\sigma \alpha^{2} \mathrm{~T} / \lambda$ ( $\alpha$ the Seebeck coefficient, $\sigma$ and $\lambda$ the electrical and thermal conductivity, respectively) is an essential element of the efficiency of a thermoelectric material for applications, which convert heat to electricity or, conversely, electric current to cooling. From the expression of the power factor, $\sigma \alpha^{2}$, it was deduced that a highly degenerated semiconductor is necessary. In order to reduce the lattice part of the thermal conductivity, various mechanisms, mainly related to the structure of the materials, were tested in new thermoelectric materials and had been the topics of different reviews. These include cage-like materials, effects of vacancies, solid solutions, complex structures (cluster, tunnel, ...), nano-structured systems. We plan to review structural aspects in the modern thermoelectric materials and include results of the very last years in such view. Moreover, as micro- and nano-composites seem to be promising to increase ZT in large size samples, we will also briefly discuss the interest of spark plasma sintering technique to preserve the micro- or nano- structure in highly densified samples.
\end{abstract}




\section{Introduction}

Thermoelectric (TE) effects include the transformation of caloric energy to electric energy or its reverse, and their applications consequently include the two aspects: (micro)cooling or electricity generation from heat sources. Search for new friendly environmental energy sources recently became of major importance in our modern societies, specially after the signature of the Kyoto protocol. Consequently, the electricity generation from waste heat via thermoelectric modules (see Seebeck effect) can be seen as a new "green" energy source. Moreover, thermoelectric materials can be used to extract heat (see Peltier effect) from microelectronic components. In the first case, the low efficiency of the thermoelectric systems has prevented their use during many years, but the situation is changing with increase of the needs (and cost) of energy and improved materials. In the latter case, classical methods (air/water) are no more appropriate due to miniaturization and high local power to dissipate. In both cases, new concepts lead, from $\sim 1995$, to rather remarkable progress, as well as the appearance of the topics in many conferences and national research programs in various countries.

The understanding of physical phenomena involved in thermoelectricity and the development of conventional TE materials occur during two main active period.

From 1821 to 1851 , the 3 TE effects (Seebeck, Peltier and Thomson) have been discovered and understood from a macroscopic point of view. Their potential for applications to temperature measurements, cooling and electricity production have also been established. Later on, from 1930 to the beginning of the sixties of the previous century, important progress occur both in the understanding of phenomena at a microscopic scale and in the discovery and optimization of presently used TE materials. However, the efficiency was not sufficient to compete with the cooling by compression/détente cycles or for economically profitable electricity production.

More recently, from the beginning of 1990's, a renewal of interest in TE appears, due to environmental concern with refrigerant gas and greenhouse effects, as well as the need to develop alternative energy sources.

The two main research directions happen to be - the development of new materials with complex or open structures, and - the development of already known materials under new low dimensionality forms (quantum wells, nano-wires, nanograins, thin films, nano-composites, ..). Among new materials having interesting TE characteristics for electricity generation from heat sources in the range 200$800^{\circ} \mathrm{C}$ we will emphasize the role of the structure and the potential of micro- and nano-structures to exceed the $14 \%$ efficiency reported by [Caillat 2004]. 


\section{The thermoelectric effects}

The first thermoelectric effect has been discovered by [Seebeck 1822] and understood later by Oersted: a potential appears at the junction of two materials a, b submitted to a gradient of temperature. The well known application of the Seebeck effect is the measurement of temperature by thermocouple. The Seebeck coefficient, $\alpha_{\mathbf{a b}}=\Delta \mathbf{V} / \Delta \mathbf{T}$, is the entropy $\mathrm{S}$ per charge carrier $\mathrm{q}$ divided by the charge: $\alpha=$ S/q. Later on, [Peltier 1834] has discovered the second effect: a temperature difference appears when a current I pass though the junctions of two different materials. There is absorption of heat $\mathrm{Q}$ at one junction and liberation of $\mathrm{Q}$ at the other junction, the Peltier coefficient is defined by $\Pi_{a b}=\mathbf{Q} / \mathbf{I}$. The third effect [Thomson 1851] occurs when both a gradient of temperature and an electric current exists simultaneously. When a current passes through a material submitted to a gradient of temperature, then the material exchanges heat with the outside medium. Conversely, a current is produced when a heat flux passes through a material submitted to a temperature gradient. The thermal flux, $\mathbf{d Q} / \mathbf{d x}$, is given by $\tau . I . d T / d x$ with $\tau$ the Thomson coefficient. The Peltier and Seebeck coefficients are related by $: \Pi=\alpha \mathbf{T}=\mathbf{Q} / \mathbf{I}$.

\section{Efficiencies, Figure of merit}

For both cooling or generation, a TE module is made of couples n,p electrically connected. Each couple includes a p-type material $(\alpha>0)$ and a n-type material $(\alpha<0)$ in which charge carriers are holes and electrons, respectively. These two materials are joined by a conducting material assumed to be with $\alpha=0$.

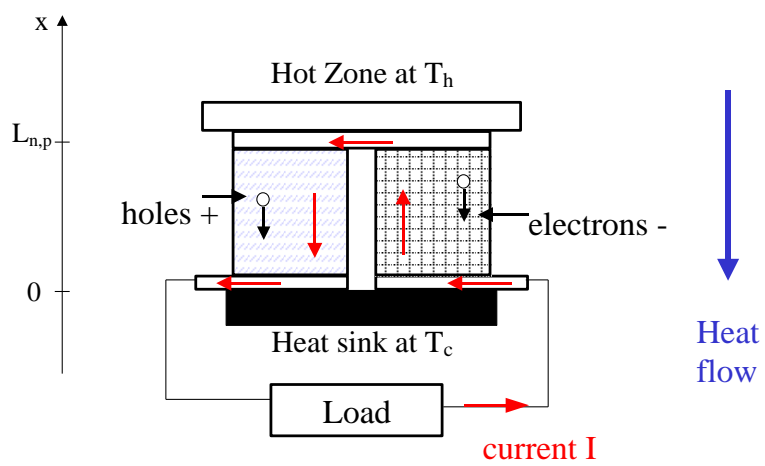

Fig. 3.1. Scheme of a TE couple for generation. 
The two branches of the couple and all other couples of the module are connected electrically in series and thermally in parallel. The scheme of principle of a couple for generation is shown in Fig. 3.1. In the case of cooling, the load is replaced by a dc-current source, which oblige the charge carriers to move from the cold zone to the hot zone in both branches. This implies a thermal flux opposite to the normal heat conduction.

The optimization of the materials needs to optimize their transport properties in order to maximize the so-called figure of merit:

$$
\mathrm{ZT}=\sigma \alpha^{2} \mathrm{~T} / \lambda
$$

with $\sigma=1 / \rho$ and $\lambda$ the electrical and thermal conductivities, respectively.

For cooling applications, the efficiency of the system is given by the coefficient of performance COP which, in an optimized system, is:

$$
C O P=\frac{\gamma T_{f}-T_{c}}{\left(T_{f}-T_{c}\right)(1+\gamma)}
$$

with $\gamma=\sqrt{1+Z T}, \mathrm{~T}_{\mathrm{h}}$ and $\mathrm{T}_{\mathrm{c}}$ the hot and cold temperatures respectively. For electricity generation, the maximum conversion efficiency is given by:

$$
\eta_{\max }=\frac{\left(T_{c}-T_{f}\right)(\gamma-1)}{T_{f}+\gamma T_{c}} .
$$

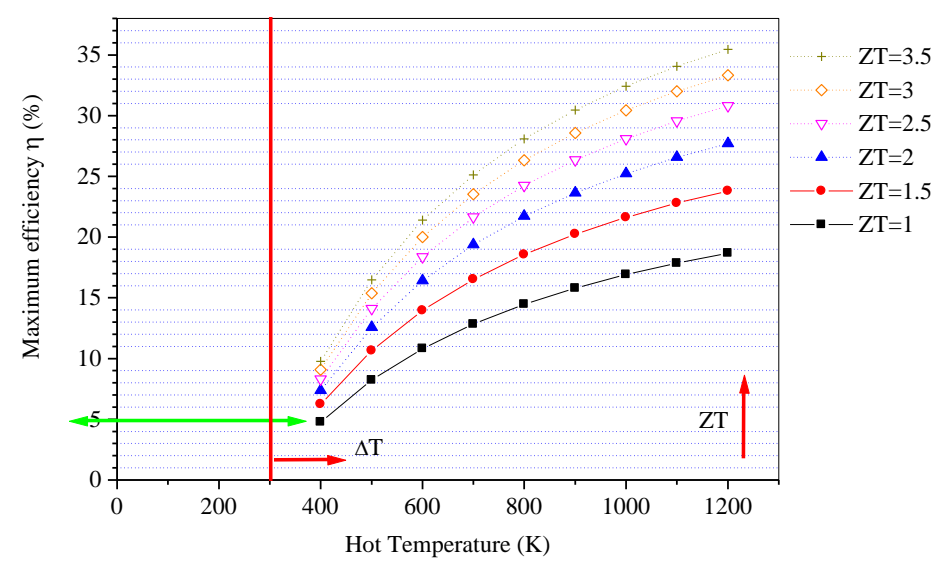

Fig. 3.2. Maximum efficiency for generation

From this expression, it s possible to estimate the maximum efficiency which can be expected for the couple versus the hot temperature (the cold one is taken as $300 \mathrm{~K}$ ) with different values of ZT (Fig. 3.2). 
The green double arrow shows that for a $\mathrm{ZT}=1$ and a temperature gradient of $100^{\circ}$, the efficiency is no more than $5 \%$. To increase it, it is necessary to increase ZT or to increase the temperature gradient: in both cases, this leads to a problem of materials: 1- to increase ZT; 2- to find materials stable at higher temperature.

In fact, the previous simple calculations assume that $\mathrm{ZT}$ is constant versus temperature, which is not correct specially if the temperature gradient is large (see below the curves of ZT for $\mathrm{n}$ - and p-type materials).

The expression of the figure of merit clearly sums up the difficulty to optimize the materials. Intuitively, it seems difficult for a material to simultaneously possesses a good electrical conductivity, characteristic of metals, and a bad thermal conductivity, characteristic of insulator. Closer examination of the power factor $\sigma \alpha^{2}$ [Gonçalves et al., in this volume] leads to consider semiconductors with a small gap and a carrier concentration in the range $\left[10^{18}-10^{21} \mathrm{~cm}^{-3}\right]$. The second parameter is the thermal conductivity which, in such semiconductors, must be reduced.

\section{Thermal conductivity, phonons}

Intuitively, a good thermal conductivity would prevent to establish a large temperature gradient. However, the thermal conductivity includes mainly two components: an electronic contribution $\lambda_{\mathrm{e}}$, due to the movement of carriers, and a lattice contribution via the phonons $\lambda_{\mathrm{L}}: \lambda=\lambda_{\mathrm{e}}+\lambda_{\mathrm{L}}$. The electronic part of the thermal conductivity is related to the electronic conductivity via the Wiedemann-Franz law:

$$
\lambda_{\mathrm{e}}=\mathrm{L}_{\mathrm{o}} \mathrm{T} \sigma, \square
$$

with $\mathrm{L}_{\mathrm{o}}$ the Lorentz factor. In metals, it is equal to the Lorentz number: $L_{0}=\frac{\pi^{2}}{3}\left(\frac{k}{e}\right)^{2}=2,45 \cdot 10^{-8} \quad \mathrm{~V}^{2} \cdot \mathrm{K}^{-2}$, value generally used as a first approximation for the TE semiconductors. Replacing $\lambda$ by its two components and with the Wiedemann-Franz, leads to:

$$
Z T=\frac{S^{2} T \sigma}{L T \sigma+\lambda_{L}} \text { or } Z T=\frac{S^{2}}{L} \frac{\lambda_{e}}{\lambda_{e}+\lambda_{L}} .
$$

This last expression shows that the optimization of ZT implies the minimization of the phonons contribution to $\lambda$. Assuming a negligible lattice contribution, from $\mathrm{ZT}=\alpha^{2} / \mathrm{L}$, a ZT of 1 or $3{ }^{1}$ would be obtained from a Seebeck coefficient of 156 $\mu \mathrm{V} / \mathrm{K}$ or $270 \mu \mathrm{V} / \mathrm{K}$, respectively. However, the minimization should not modify the electrical conductivity (as ZT increases with $\lambda_{\mathrm{e}} / \lambda_{\mathrm{L}}$ ). This leads to the proposition of [Slack 1995] to check materials which conducts electricity as a crystal and

${ }^{1} \mathrm{ZT}=3$ correspond to a $\mathrm{COP}$ of refrigeration of 1.1 , typical of a compression fridge 
heat as a glass, so-called "Phonon Glass Electron Crystal" (PGEC). This implies to find selective diffusion process which affects more the phonons than the carriers. Various physical process inducing significant phonon diffusion have been tested on TE materials, let us quote those that are somehow related with the structure:

- a complex crystalline structure will increase the number of optical phonon modes, whereas the heat is mainly conducted by acoustic phonons;

- the insertion of heavy atoms in empty cages of crystalline structure may let them rattle independently of the lattice and so, create new phonon modes (weakly dispersive optical modes);

- solid solutions between different materials with the same structure increase the disorder and create an important phonon diffusion by mass fluctuations on the sites [Abeles 1963], such mass fluctuations can also be obtained by vacancy creation in the material;

-impurities and point defects will diffuse phonons [Callaway 1960], [Klemens 1960], [Worlock 1966]: this leads to study micro- or nano-composites materials (mixing of a good TE material with another neutral for TE), or use "exotic" synthesis or shaping techniques inducing large amount of such defects,

- grain boundaries will affect phonons (and also electrical conductivity), this leads to study nano-crystalline materials to increase the number of such boundaries or even to reduce the mean free path of phonons (when the sizes of the nano-grains are comparable with that of the mean free path of phonons).

That different processes are not exclusives and some of them can be created simultaneously in the same TE material; some examples are given in the chapter by [Gonçalves et al., in this volume].

\section{Conventional TE materials}

From 1960, all actually used TE materials (see Table 5.1) were known and their performance, bound to a stagnant ZT to $\sim 1$, have not much changed up to 1990 .

The main market applications, were based on $\mathrm{Bi}_{2} \mathrm{Te}_{3}$ - type of material mainly used for cooling. Let us remark that no material was efficient in the temperature range 400-700K. At higher temperature, PbTe and TAGS (Te-Ag-Ge-Sb) have ZT $\sim 1$ in $\mathrm{n}$ - and $\mathrm{p}$ - type respectively. 


\begin{tabular}{llllllll}
\hline & $\mathrm{Bi}-\mathrm{Sb}$ & $\mathrm{Bi}_{2} \mathrm{Te}_{3}-\mathrm{Sb}_{2} \mathrm{Te}_{3}$ & $(\mathrm{Bi}, \mathrm{Sb})_{2}(\mathrm{Te}, \mathrm{Sb})_{3}$ & - & $\mathrm{PbTe}$ & $\begin{array}{l}\mathrm{Te}-\mathrm{Ag}- \\
\mathrm{Ge}-\mathrm{Sb}\end{array}$ & $\mathrm{Si}-\mathrm{Ge}$ \\
\hline Type & $\mathrm{n}$ & $\mathrm{n}, \mathrm{p}$ & $\mathrm{n}, \mathrm{p}$ & - & $\mathrm{n}$ & $\mathrm{p}$ & $\mathrm{n}, \mathrm{p}$ \\
$\mathrm{T}_{\mathrm{u}}(\mathrm{K})$ & 200 & $<300$ & $\sim 300-400$ & - & 700 & 750 & 1000 \\
$\mathrm{ZT}_{\text {at }} \mathrm{T}_{\mathrm{u}}$ & $1.1(\mathrm{H})$ & 0.8 & 0.9 & - & 0.8 & 1.1 & 0.6 \\
\hline
\end{tabular}

Table 5.1. ZT of conventional materials at their optimal temperature of use $T_{u}(H$ means a value obtained under a magnetic field)

\section{Recent bulk TE materials}

\subsection{ADP (Atomic Displacement Parameter)}

In solids, the atoms don't move only at zero temperature. At finite temperature, the atoms vibrate around their equilibrium position on their crystallographic site, the mean square displacement amplitude of such atoms is called the Atomic Displacement Parameter, ADP, which is useful to estimate the minimum value of the lattice contribution to the thermal conductivity and is thus of interest in TE materials.

The vibrations of the atoms are generally non isotropic and this anisotropy is taken into account by a tensor of the ADP, noted $U_{\mathrm{ij}}$. These $\mathrm{U}_{\mathrm{ij}}$ are described by the ellipsoids of vibrations centered on each atom with an extension in one direction corresponding to the amplitude of the vibration in that direction. An isotropic ADP $U_{\text {iso }}$ can be defined for each site, which is the mean value of the $U_{i j}$ in all the directions of the space. Its amplitude allows to compare the overall movements of the different atoms of the structure. Generally the $U_{\text {iso }}$ tends toward zero at zero temperature, and if not, this may indicate some static disorder on the site.

The minimal value of the lattice part of the thermal conductivity is given by $\lambda_{\mathrm{L}}=(1 / 3) \mathrm{C}_{\mathrm{v}} \mathrm{v}_{\mathrm{S}} \mathrm{d}$, with $\mathrm{v}_{\mathrm{S}}$ the sound speed, $\mathrm{d}$ the mean free path of phonons and $\mathrm{C}_{\mathrm{v}}$ the specific heat estimated from the Dulong and Petit law

$$
C \underset{T \rightarrow \infty}{\rightarrow} 3 R=3 N_{A} k_{B}
$$

(with $\mathrm{R}$ the constant of gas, $\mathrm{N}_{\mathrm{A}}$ the Avogadro number). In the case of a cage like material, like $\mathrm{LaB}_{6}$, (Fig. 6.1), the specific heat has been calculated from ADP of $\mathrm{La}$ and $\mathrm{B}$ atoms. 


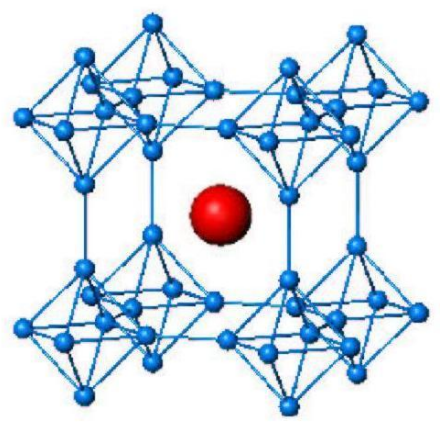

Fig. 6.1. Cage like structure of $\mathrm{LaB}_{6}$, the $\mathrm{La}$ atom $\bullet$ is surrounded by $\mathrm{B} \bullet$ groups.

The La atom is considered as an Einstein oscillator in a solid of Debye of Batoms. $C_{V}=f . C_{D}+\left((1-f) C_{E}\right.$ with $f$ the fraction of atoms contributing to the solid of Debye and (1-f) that of Einstein oscillators; $\theta_{\mathrm{D}}$ and $\theta_{\mathrm{E}}$, the Debye and Einstein temperatures respectively:

$$
C_{D}=9 N_{A} k_{B}\left(\frac{T}{\theta_{D}}\right)^{3} \int_{0}^{\theta_{D} / T} \frac{x^{4} e^{x}}{\left(e^{x}-1\right)^{2}} d x
$$

and

$$
C_{E}=3 N_{A} k_{B}\left(\frac{\theta_{E}}{T}\right)^{2} \frac{e^{\theta_{E} / T}}{\left(1-e^{\theta_{E} / T}\right)^{2}}
$$

\subsection{Cage like TE materials}

Cage like TE materials have a rigid sub-lattice responsible for the electrical conductivity and large empty cages. When the cages are filled with heavy atoms, these atoms, weakly bound to the cage, can vibrate inside with a strong amplitude of vibrations. Initially it has been proposed that these vibrations are incoherent ("rattling") and act as traps for the acoustic phonons and consequently decrease the thermal conductivity. According to more recent work, the vibrations of the inserted atom are optical phonons (coherent vibrations) mainly without dispersion (localized character) and with a weak energy which strongly interfere with acoustic phonons to decrease the thermal conductivity.

The two most studied families of cage like TE materials are the filled skutterudites $\mathrm{A}_{\mathrm{y}} \mathrm{M}_{4} \mathrm{X}_{12}$ (A: an electropositive element, $\mathrm{M}$ a metal and $\mathrm{X}=\mathrm{P}, \mathrm{As}, \mathrm{Sb}$ ) and the clathrates of the type $\mathrm{A}_{8} \mathrm{Y}_{16} \mathrm{X}_{30}$ (X and $\mathrm{Y}$ being actually mainly $\mathrm{Ga}$ and $\mathrm{Ge}$ ), both of them leading to increased values of $\mathrm{ZT}$. 


\section{2.a. Skutterudites}

In the skutterudite, the atom A fills the cubic structure (space group $\operatorname{Im} 3$ ) of the binary $\mathrm{CoX}_{3}$, which leads to the ternary filled structure $\mathrm{A}_{\mathrm{y}} \mathrm{M}_{4} \mathrm{X}_{12}$ [Jeitschko 1977] (Fig. 6.2).

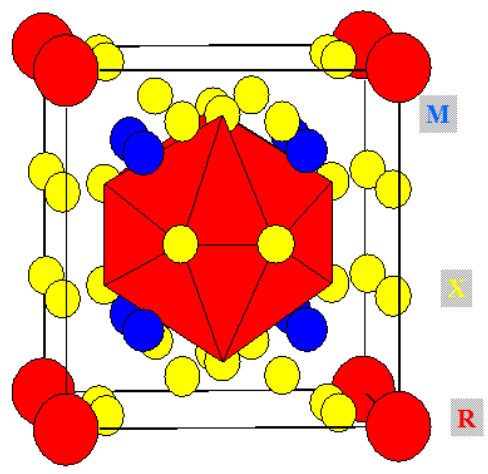

Fig. 6.2. Structure of filled skutterudite $A_{y} M_{4} X_{12}$

Atoms of various oxidation numbers (single valence $\mathrm{K}, \mathrm{Na}$; divalent $\mathrm{Ca}$, $\mathrm{Sr}, \mathrm{Ba}$, trivalent $\mathrm{La}, \mathrm{Ce}, \mathrm{Pr}, \mathrm{Nd}$, Th, U; mixed valent $\mathrm{Yb}$ [Bérardan 2003]) can fill the cage with an occupation rate which depends on the nature of $\mathrm{A}(\sim 1$ with $\mathrm{K}$ and $\mathrm{Na}$ [Leithe Jasper 2003], but smaller with rare earths) and strongly on the nature of $\mathrm{M}$ $(\sim 0.2$ with $\mathrm{Co}$ and $\sim 0.9$ with $\mathrm{Fe})$ in rare earth based series (Table 6.1).

\begin{tabular}{llllll}
\hline $\mathrm{A}=\mathrm{Ba}$ & $\mathrm{La}$ & $\mathrm{Ce}$ & $\mathrm{Eu}$ & $\mathrm{Yb}$ & $\mathrm{Tl}$ \\
\hline 0.44 & 0.23 & 0.1 & 0.54 & 0.25 & 0.22 \\
[Chen 2001] & {$[$ Nolas 1998] } & [Chen 1997] & [Berger 2001] & [Anno 2000] & [Sales 2000] \\
\hline
\end{tabular}

Table 6.1. Occupation limits of $\mathrm{A}$ in $\mathrm{A}_{\mathrm{y}} \mathrm{Co}_{4} \mathrm{Sb}_{12}$

The cage in $\mathrm{CeFe}_{4} \mathrm{Sb}_{12}$ is well evidenced when looking on the distances between atoms (Fig. 6.3). The distance $\mathrm{d}(\mathrm{Ce}-\mathrm{Sb})=3.39 \AA$, and the covalent radius $\mathrm{R}$ of $\mathrm{Sb}$ $(1 / 2 \mathrm{~d}(\mathrm{Sb}-\mathrm{Sb})=1.46 \AA)$ gives $\mathrm{d}-\mathrm{R}=1.93 \AA \mathrm{>}$ ionic radius of $\mathrm{Ce}=1.14 \AA$. 


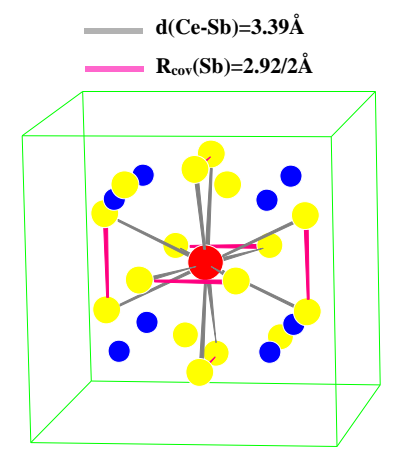

Fig. 6.3. Distances and cage in $\mathrm{CeFe}_{4} \mathrm{Sb}_{12}$

Consequently, two effects can affect $\lambda_{\mathrm{L}}$ : a strong vibration of $\mathrm{A}$, seen by neutron diffraction [Sales 1997][Chakoumakos 1999)] (Fig. 6.4), and a variable vacancy concentration rate in $\mathrm{A}_{\mathrm{y}}(\mathrm{Fe}, \mathrm{Co})_{4} \mathrm{Sb}_{12}$.

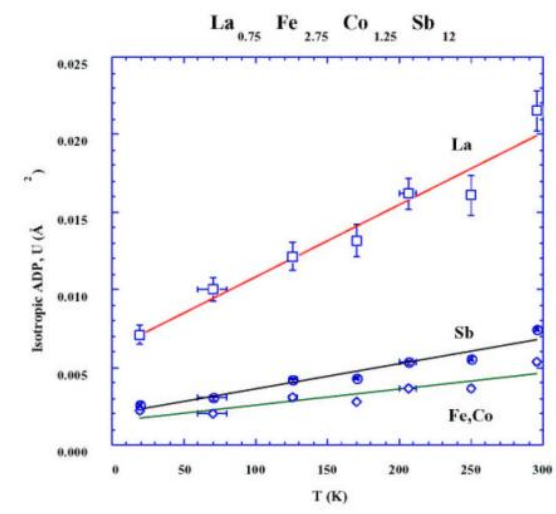

Fig. 6.4. Isotropic $\mathrm{ADP}$ in $\mathrm{La}_{\mathrm{y}}(\mathrm{Fe}, \mathrm{Co})_{4} \mathrm{Sb}_{12}$.

As can be seen in Fig. 6.4, the ADP of $\mathrm{La}$ in $\mathrm{La}_{\mathrm{y}}(\mathrm{Fe}, \mathrm{Co})_{4} \mathrm{Sb}_{12}$ is much higher than that of $\mathrm{M}$ and $\mathrm{Sb}$ atoms. The thermal conductivity is strongly reduced in the ternaries as compared to binaries. The smallest $\lambda_{\mathrm{L}}$ appears in antimonides, i.e., when the cage is larger (due to increase lattice parameter) and consequently when the amplitude of vibration is stronger (Fig. 6.5) [Fleurial 1997]. 
In the phenomenological model of [Sales 1999], [Sales 2000] for skutterudites, the filler atom is treated as an Einstein oscillator and the $(\mathrm{M}, \mathrm{X})$ lattice as a solid of Debye.

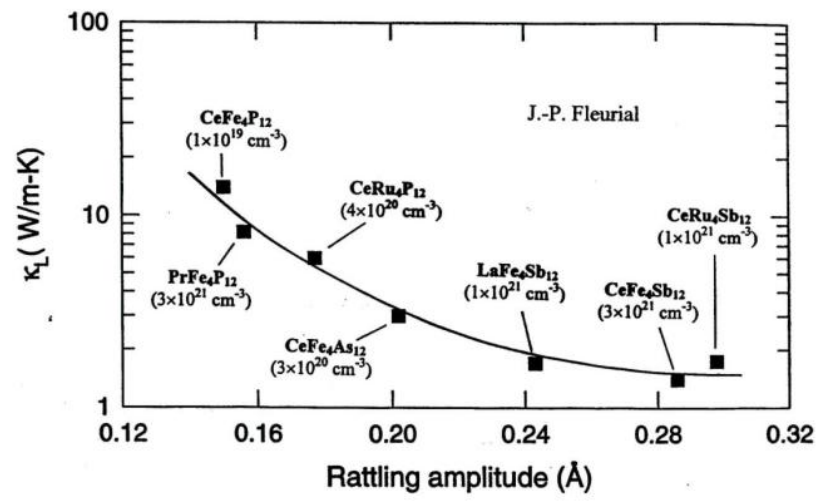

Fig. 6.5. Thermal conductivity versus the amplitude of rattling.

\begin{tabular}{llllll}
\hline & $\mathrm{Samples}_{2}$ & Type & highest $\mathrm{ZT}$ & $\mathrm{T}$ \\
$\mathrm{ZT}$ & $(\mathrm{K})$ & Ref. \\
\hline $\mathrm{B}$ & $\left(\mathrm{CoSb}_{3}\right)_{0.75}+\left(\mathrm{FeSb}_{2}\right)_{0.25}$ & $\mathrm{n}$ & 0.37 & 773 & [Katsuyama 2000] \\
$\mathrm{B}$ & $\mathrm{Co}_{0.94} \mathrm{Ni}_{0.04} \mathrm{Sb}_{3}$ & $\mathrm{n}$ & 0.5 & 750 & [Katsuyama 2003] \\
$\mathrm{B}$ & $\mathrm{CoSb}_{3}$ & $\mathrm{p}$ & 0.21 & 600 & [Katsuyama 1998] \\
$\mathrm{B}$ & $\mathrm{CoSb}_{3}+0.75 \% \mathrm{Te}$ & $\mathrm{n}$ & 0.5 & 600 & [Wojciechowski 2001] \\
$\mathrm{B}$ & $\mathrm{CoSb}_{3}+4 \% \mathrm{Te}$ & $\mathrm{n}$ & 0.8 & 750 & [Nagamoto 1998] \\
$\mathrm{B}$ & $\mathrm{IrSb}_{3}$ & $\mathrm{p}$ & 0.15 & 800 & [Slack 1994] \\
$\mathrm{T}$ & $\mathrm{Ba}_{0.24} \mathrm{Co}_{4} \mathrm{Sb}_{11.87}$ & $\mathrm{n}$ & 1.1 & 850 & [Chen 2001] \\
$\mathrm{T}$ & $\mathrm{Ba}_{0.3} \mathrm{Co}_{3.95} \mathrm{Ni}_{0.05} \mathrm{Sb}_{12}$ & $\mathrm{n}$ & 1.2 & 800 & [Dyck 2002] \\
$\mathrm{T}$ & $\mathrm{Ca}_{\mathrm{y}} \mathrm{Co}_{4-\mathrm{x}} \mathrm{Ni}_{\mathrm{x}} \mathrm{Sb}_{12}$ & $\mathrm{p}$ & 1 & 800 & [Puyet 2005] \\
$\mathrm{T}$ & $\mathrm{Ce}_{0.28} \mathrm{Co}_{2.5} \mathrm{Fe}_{1.5} \mathrm{Sb}_{12}$ & $\mathrm{p}$ & 1.1 & 800 & [Tang 2001] \\
$\mathrm{T}$ & $\mathrm{Ce}_{\mathrm{x}} \mathrm{Fe}_{3.5} \mathrm{Co}_{0.5} \mathrm{Sb}_{12}$ & $\mathrm{p}$ & $1.4(1.2)^{2}$ & 870 & [Fleurial 1996] \\
$\mathrm{T}$ & $\mathrm{Eu}_{0.42} \mathrm{Co}_{4} \mathrm{Sb}_{11.37} \mathrm{Ge}_{0.50}$ & $\mathrm{n}$ & 1.1 & 700 & [Lamberton 2002] \\
$\mathrm{T}$ & $\mathrm{In}_{0.25} \mathrm{Co}_{4} \mathrm{Sb}_{12}$ & $\mathrm{n}$ & 1.2 & 570 & [He 2006] \\
$\mathrm{T}$ & $\mathrm{In}_{0.2} \mathrm{Ce}_{0.2} \mathrm{Co}_{4} \mathrm{Sb}_{12}$ & $\mathrm{n}$ & 1.7 & 570 & [He 2005] \\
$\mathrm{T}$ & $\mathrm{La}_{\mathrm{x}} \mathrm{Fe}_{4-\mathrm{y}} \mathrm{Co}_{\mathrm{y}} \mathrm{Sb}_{12}$ & $\mathrm{p}$ & 1 & 800 & [Sales 1996] \\
$\mathrm{T}$ & $\mathrm{Nd}_{\mathrm{x}} \mathrm{Co}_{4} \mathrm{Sb}_{12}$ & $\mathrm{n}$ & 0.45 & 700 & [Kuznetsov 2003] \\
$\mathrm{T}$ & $\mathrm{Tl}_{\mathrm{x}} \mathrm{Co}_{4} \mathrm{Sb}_{12}$ & $\mathrm{n}$ & 0.2 & 300 & [Sales 2000] \\
$\mathrm{T}$ & $\mathrm{Yb}_{0.8} \mathrm{Fe}_{3.4} \mathrm{Ni}_{0.6} \mathrm{Sb}_{12}$ & $\mathrm{p}$ & 1 & 800 & [Anno 2002] \\
$\mathrm{T}$ & $\mathrm{Yb}_{0.19} \mathrm{Co}_{4} \mathrm{Sb}_{12}$ & $\mathrm{n}$ & $>1$ & 600 & [Nolas 2000] \\
$\mathrm{T}$ & $\left({\mathrm{Ce}, \mathrm{Yb}_{0.4} \mathrm{Fe}_{3} \mathrm{CoSb}_{12}}\right.$ & $\mathrm{p}$ & 1 & 800 & [Bérardan 2005] \\
\hline
\end{tabular}

Table 6.2. Highest ZT in binary (B) and ternary (T) skutterudites

${ }^{2}$ calculated values of 1.2 from experimental data 
By appropriate substitutions, keeping the semiconducting (semi-metallic) state, the values of ZT have been strongly improved from a maximum value of $\sim 0.8$ (Table 6.2) in $\mathrm{CoSb}_{3}$ to higher than 1 in various series, with both $\mathrm{n}$ - and $\mathrm{p}$ - type (Table $6.2)$.

Let us note that the possibility to obtain both types, with high ZT, in the same temperature range, with chemically rather similar materials is a positive point of these series, as similar behaviors is expected when used in applications.

\section{2.b Clathrates $A_{8} \mathrm{Ga}_{16} \mathrm{Ge}_{30}(\mathrm{~A}=\mathrm{Ba}, \mathrm{Eu}, \mathrm{Sr})$}

Clathrates are compounds made by inclusion of molecules of one species in cavity of a crystalline lattice of another species: they consequently are cage like compounds. In this article we are only concerned with semiconducting clathrates. The family of clathrates [Kaspar 1965], derived from the binary $\mathrm{A}_{8} \mathrm{X}_{46}(\mathrm{~A}=$ alkaline or alkaline earth, $\mathrm{X}=\mathrm{Si}, \mathrm{Ge}$ ), comprise numerous structures built from complex polyhedron of $\mathrm{X}$ elements $\left(\mathrm{X}_{20}, \mathrm{X}_{24}, ..\right)$ filled by the electropositive element A (Fig. 6.6).

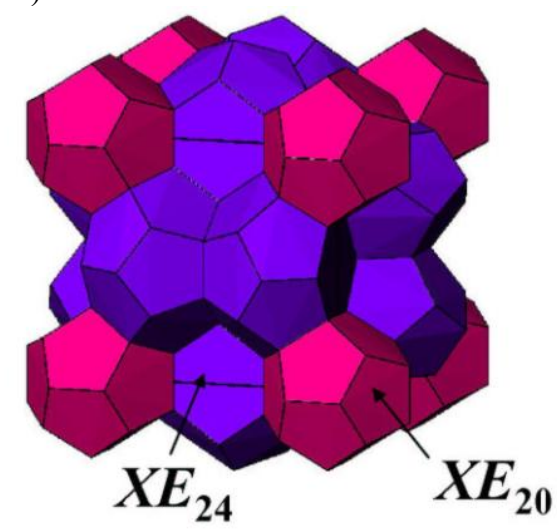

Fig. 6.6. The 2 types of polyhedron $X_{20}$ and $X_{24}$ around A atom in the type I clathrate $\mathrm{A}_{8} \mathrm{Ga}_{16} \mathrm{Ge}_{30}$.

The type I structure, made from 2 polyhedron $\mathrm{X}_{20}$ and $6 \mathrm{X}_{24}$, leads to a metallic character; a semiconducting state is obtained by substituting $\mathrm{X}$ by an element which accepts the electrons from A-metal. If $\mathrm{A}$ is divalent this means to replace 16 $\mathrm{Ge}$ (Si) by $16 \mathrm{Ga}$ which leads to $\mathrm{A}^{2+}{ }_{8} \mathrm{Ga}^{-}{ }_{16} \mathrm{Ge}^{\mathrm{o}}{ }_{30}$ (cubic, space group Pm3n). In the cage $\mathrm{X}_{24}$, the inserted atom has strong vibration amplitudes (Fig. 6.7) [Chakoumakos 2000] 


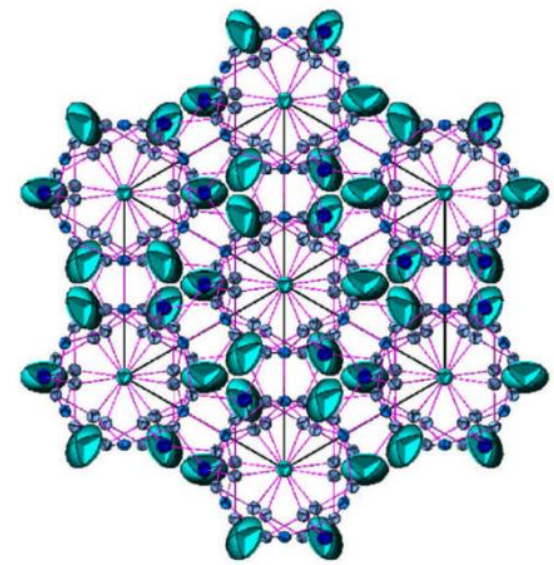

Fig. 6.7. View, along 111 projection, of the ellipsoids of movement of $\mathrm{Sr}$ in $\mathrm{Sr}_{8} \mathrm{Ga}_{16} \mathrm{Ge}_{30}$.

Consequently, the ADP values on the site $\mathrm{Sr} 2$ are higher than that on site Sr1 (Fig. 6.8), the strong residual component at low temperature being due to static disorder on this site. The filling of the cages induces strong decreases of the thermal conductivity which becomes as low as in glass or quartz [Nolas 1998].

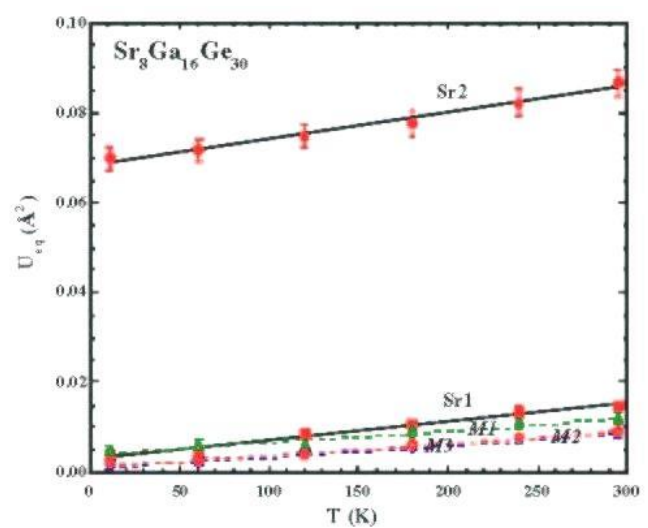

Fig. 6.8. Values of ADP for the different sites in $\mathrm{Sr}_{8} \mathrm{Ga}_{16} \mathrm{Ge}_{30}$.

Presently, the type I has lead to ZT values highest than 1 [Anno 2002],[Bentien 2003]. 


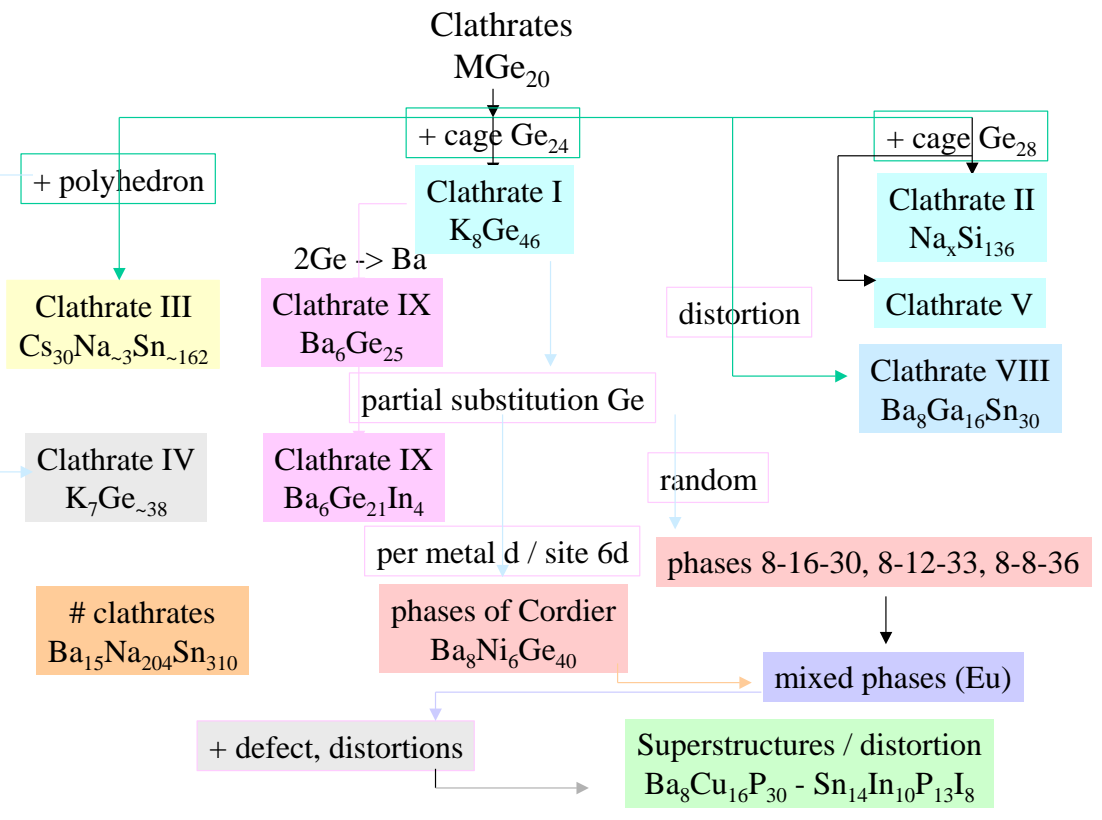

Fig. 6.9. Clathrates filiations.

Other iso-electronic substitutions (Al, In) [Mudryk 2002], [Blaque 2001] lead to semiconducting materials. Another possibility is to play on stoechiometry, for instance: $\mathrm{Eu}_{8} \mathrm{Ga}_{16+/ \mathrm{x}} \mathrm{Ge}_{30-/+\mathrm{x}}$ [Grin 2003] or to compensate non iso-electronic substitution by vacancies in $\mathrm{Ba}_{8} \mathrm{Zn}_{\mathrm{x}} \mathrm{Ge}_{46-\mathrm{x}-\mathrm{y}}[]_{\mathrm{y}}$, with [] a vacancy [Deng 2007]. Presently, only Eu- and Ba- based clathrates have lead to good ZT values in these materials, in which the control of the stoechiometry is critical, not only for TE properties but also for the appearance of parasitic phases.

The chemistry of these phases is very rich (Fig. 6.9, simplified version of [Mudryk 2002]), the studies of their physical properties should lead to new interesting compounds for TE properties.

\section{2.c Penta- Hexa- tellurides}

Three series of penta-tellurides and one hexa-telluride have been examined for TE properties.

In $\mathrm{Tl}_{2} \mathrm{MTe}_{5}(\mathrm{M}=\mathrm{Ge}, \mathrm{Sn})$, one $\mathrm{Tl}$ site $\left(\mathrm{Tl}_{1}\right)$ does not have close nearest neighbors whereas the $\left(\mathrm{Tl}_{2}\right)$ site has (Fig. 6.10). 


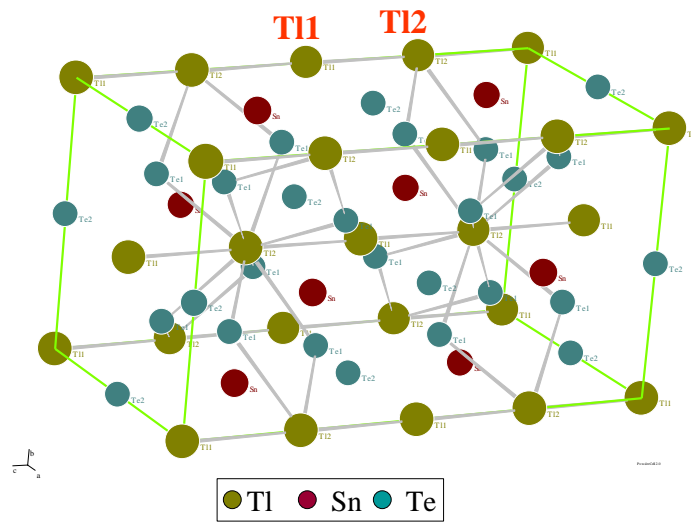

Fig. 6.10. Structure of $\mathrm{Tl}_{2} \mathrm{SnTe}_{5}$ and neighboring of $\mathrm{Tl}$ in site 2 and 1 .

Consequently, the ADP of T11 are larger than that of Tl in site 2. ZT values of $\sim 0.6$ have been obtained [Sharp 1999]. No solid solutions have been checked until now.

The second system $\operatorname{Re}_{2} \mathrm{Te}_{5}\left(\mathrm{Re}_{6} \mathrm{Te}_{15}\right)$ has a complex structure (space group Pbca), with 84 atoms/unit cell and has some similitude with Chevrel's phases (octahedral clusters $\mathrm{Re}_{6}$ and large empty cages). $\mathrm{n}$ - and $\mathrm{p}$ - type are possible by appropriate doping. The last penta-telluride $\mathrm{Ag}_{9} \mathrm{TlTe}_{5}$ has a complex structure. The thermal conductivity of this material is smaller than that of other good TE materials like $\mathrm{Bi}_{2} \mathrm{Te}_{3}$ or TAGS [Kurosaki 2005]. $\mathrm{Ag}_{9} \mathrm{TlTe}_{5}$ has a $\mathrm{ZT}$ of 1.2 at $700 \mathrm{~K}$. The hexatelluride $\mathrm{Tl}_{9} \mathrm{BiTe}_{6}$ has also a very weak thermal conductivity and a ZT of 1.2 at $500 \mathrm{~K}$, a temperature where $\mathrm{Bi}_{2} \mathrm{Te}_{3}$-based materials don't work [Wolfing 2001]. The potential of these materials is interesting from academic point of view but environmental constraints will prevent their use in devices.

\section{2.d Phases with Mo clusters}

The structure of Chevrel's phases is built from a three-dimensional network of pseudo-cubic clusters (Fig. 6.11) $\mathrm{Mo}_{6} \mathrm{X}_{8}(\mathrm{X}=\mathrm{S}, \mathrm{Se}, \mathrm{Te})$ and its versatility authorizes the formation of various representatives. 


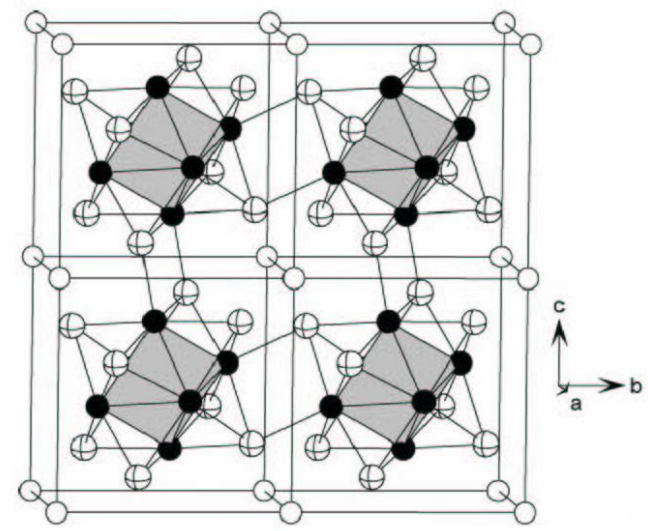

Fig. 6.11. Structure of $\mathrm{Mo}_{6} \mathrm{X}_{8}$ (Mo: $\bigcirc, \mathrm{X}: \mathrm{Q}$, empty sites $\mathrm{O}$ can be filled by $\mathrm{Pb}, \mathrm{Cu}, .$.

The clusters form cavities or channels which can be intercalated by various elements in such a way that it is possible to modify them from metallic in $\mathrm{Mo}_{6} \mathrm{X}_{8}$ to semiconductor for a Valence Electron Concentration (VEC) of 24. Under these conditions, interesting TE properties can be expected and a ZT of 0.6 (at the high temperature of $1150 \mathrm{~K}$ ) has been found in $\mathrm{Cu}_{3.1} \mathrm{Mo}_{6} \mathrm{Se}_{8}$ by studying the series $\mathrm{M}_{\mathrm{x}} \mathrm{Mo}_{6} \mathrm{Se}_{8}(\mathrm{M}=\mathrm{Cu}, \mathrm{Cu} / \mathrm{Fe}, \mathrm{Ti})$ [Caillat 1999]. Other compounds of these series have high power factors, like $\mathrm{Ti}_{0.3} \mathrm{Mo}_{5} \mathrm{RuSe}_{8}$ [McGuire 2006] or $\left(\mathrm{Cu}_{\mathrm{y}} \mathrm{Mo}_{6} \mathrm{Se}_{8}\right)_{1-}$ ${ }_{x}\left(\mathrm{Mo}_{4} \mathrm{Ru}_{2} \mathrm{Se}_{8}\right)_{\mathrm{x}}$ [Schmidt 2007]. This shows the potential of these series, specially with the possibility to replace Mo by $\mathrm{Ru}, \mathrm{Rh}$, Re to find good TE materials, of nand p- type, stable at high temperatures $(\sim 1200 \mathrm{~K})$.

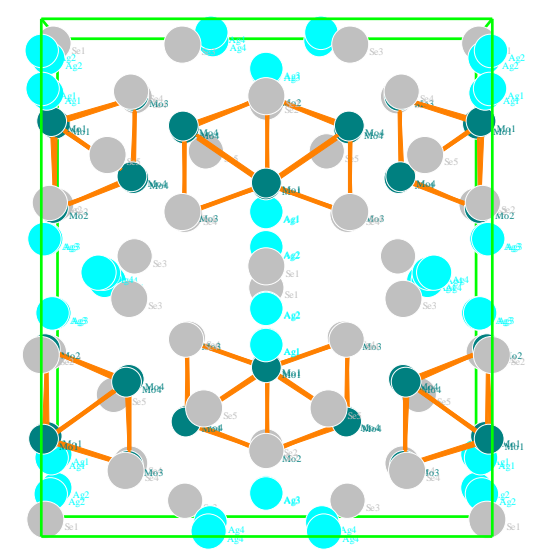

Fig. 6.12. Structure of $\mathrm{Ag}_{3.6} \mathrm{Mo}_{9} \mathrm{Se}_{11}(\bullet \mathrm{Mo}, \bullet \mathrm{Se}, \bullet \mathrm{Ag}),-$ Mo clusters 
In the phase with $\mathrm{Mo}_{9} \mathrm{Se}_{11}$ clusters, the structure owns tunnel, and the insertion of atoms $(\mathrm{Ag}, \mathrm{Cs}, \mathrm{Cl})$ in cages [Gougeon 2004 ](Fig. 6.12) lead to semiconducting or semi-metallic compounds, depending on the number of electrons per clusters. These characteristics should be favorable for TE properties, which have yet not been studied in details.

However, a Seebeck coefficient of $72 \mu \mathrm{V} / \mathrm{K}$ and a weak resistivity have been reported in $\mathrm{Ag}_{3.6} \mathrm{Mo}_{9} \mathrm{Se}_{11}$ [Potel 2008].

Many other structural families may have empty cages in which the insertion of atoms with various oxidation degrees may lead to a semiconducting state, a prerequisite for good TE properties.

\subsection{Phases with vacancies}

\section{3.a. Half Heusler}

The cubic structure of the Heusler phases $\mathrm{X}_{2} \mathrm{YZ}$ (space group Fm3m) consists in 4 interpenetrated face centered cubic lattices in $\mathrm{A}(0,0,0) ; \mathrm{B}=(1 / 4,1 / 4,1 / 4), \mathrm{C}=(1 / 2,1 / 2,1 / 2)$, et $\mathrm{D}=(3 / 4,3 / 4,3 / 4)$, with one occupancy of the sites $\mathrm{A}=\mathrm{Y} ; \mathrm{B} \& \mathrm{D}=\mathrm{X}$ and $\mathrm{C}=\mathrm{Z}$. If one of the equivalent sites $(1 / 4,1 / 4,1 / 4)$ or $(3 / 4,3 / 4,3 / 4)$ is empty the Half Heusler phase (F-43m) forms (Fig. 6.13).
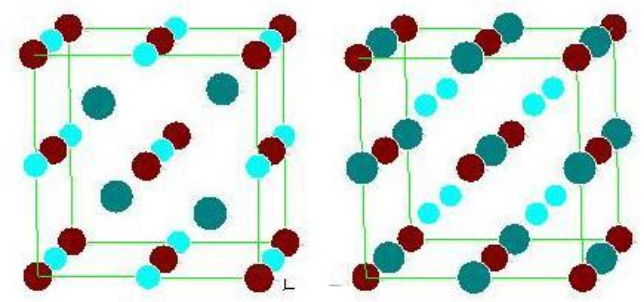

Fig. 6.13. Structures of the Heusler phases of $\mathrm{Zr}$, Ni, Sn: half Heusler on left, Heusler on right ( $\mathrm{Sn}, \bullet \mathrm{Zr}, \bullet \mathrm{Ni})$.

Among these compounds, those with 18 valence electrons have a band structure of semiconductor and often high Seebeck coefficients.

To decrease the thermal conductivity, complex substitutions with increased phonons diffusion by mass fluctuations, have been used with success (Fig. 6.14). 


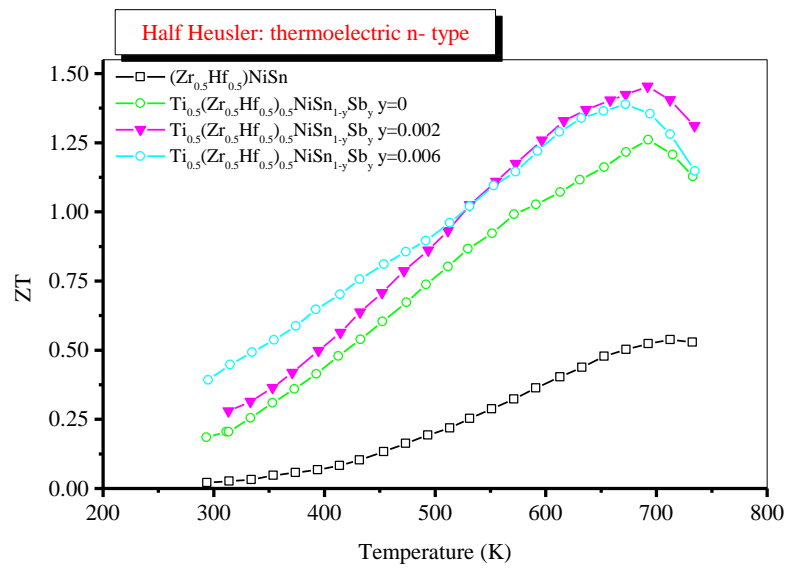

Fig. 6.14. Effect of substitutions in the half Heusler $\mathrm{ZrNiSn}$

For instance, from TiNiSn $(\mathrm{ZT}=0.4$ at $750 \mathrm{~K})$ and $\mathrm{ZrNiSn}$, the n-type compound $\mathrm{Hf}_{0,5} \mathrm{Zr}_{0,5} \mathrm{Ni}_{0,8} \mathrm{Pd}_{0,2} \mathrm{Sn}_{0,99} \mathrm{Sb}_{0,01}$ has maximum of $\mathrm{ZT}$ of 0.7 at $800 \mathrm{~K}$ and the n-type compound $\mathrm{Ti}_{0,5}\left(\mathrm{Zr}_{0,5} \mathrm{Hf}_{0,5}\right) \mathrm{NiSn}_{0,98} \mathrm{Sb}_{0,02}$ has a $\mathrm{ZT}>1.4$ at $700 \mathrm{~K}$ [Shutoh 2003].

Other systems like VFeSb (ZT=0.11 at $900 \mathrm{~K})$ have been intensively studied [Jodin 2004], but other substitutions should be examined, as simple substitutions like $\mathrm{V}_{0.95} \mathrm{Ti}_{0.05} \mathrm{FeSb}$ lead to a ZT (p-type) of 0.4 at $600 \mathrm{~K}$.

In these series, LnPdSb- type compounds $(\mathrm{Ln}=\mathrm{Sr}, \mathrm{Y}$, rare earths, specially $\mathrm{Er})$ have high Seebeck coefficients below 300K [Mastronardi 1999], [Oestreich 2003], which could lead to interesting substituted materials for cooling.

\section{3.b. $\mathrm{Zn}_{4} \mathrm{Sb}_{3}$}

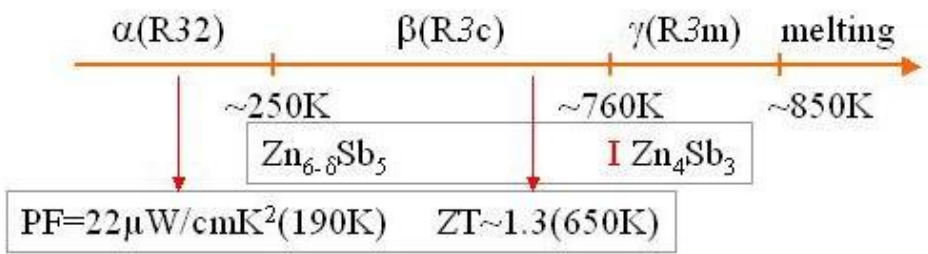

Fig. 6.15. Scheme of structural and Te properties of $\mathrm{Zn}_{4} \mathrm{Sb}_{3}$.

$\mathrm{Zn}_{4} \mathrm{Sb}_{3}$ exists under three crystallographic varieties: $\alpha$-phase stable below $-10^{\circ} \mathrm{C}$, $\beta$-phase from $-10^{\circ} \mathrm{C}$ to $492^{\circ} \mathrm{C}$ and $\gamma$-phase from $492^{\circ} \mathrm{C}$ to the melting temperature of $566^{\circ} \mathrm{C}$. The structural and TE properties are summarized in Fig. 6.15. 
The $\beta$-phase leads to TE materials (p-type), with a high ZT of 1.3 at $\sim 650 \mathrm{~K}$ [Caillat 1997], further increased to 1.4 at $525 \mathrm{~K}$ by substitution in $\mathrm{Zn}_{3.2} \mathrm{Cd}_{0.8} \mathrm{Sb}_{3}$ [Caillat 1999a].

In $\mathrm{Zn}_{4} \mathrm{Sb}_{3}$ the observation of vacancies, $\mathrm{Zn}$-interstitials and of 2 types of $\mathrm{Sb}$ atoms (spherical ion $\mathrm{Sb}^{3-}$ and dimers $\mathrm{Sb}^{4-}$ ) (Fig. 6.16) induce a strong disorder [Snyder 2004] (in fact the composition is $\sim \mathrm{Zn}_{6-\mathrm{w}} \mathrm{Sb}_{5}$ ) which contribute to the decrease of the thermal conductivity.

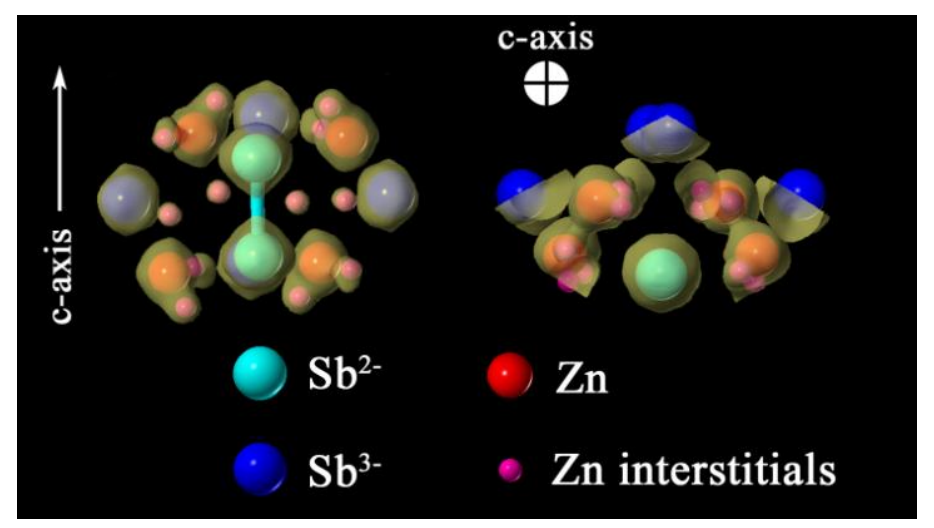

Fig. 6.16. Disorder in the structure of $\mathrm{Zn}_{4} \mathrm{Sb}_{3}$.

A phonon mode of low energy has been associated to Sb dimers [Schweika 2007]. It does not seem that doping lead to achieving the n-type.

\subsection{Complex solid solutions derived from conventional materials}

\section{4.a. $\mathrm{Bi}_{2} \mathrm{Te}_{3}$ - derivatives}

$\mathrm{As} \mathrm{Bi}_{2} \mathrm{Te}_{3}$ is the archetype of TE materials used for cooling applications, few derivatives systems have been studied.

At low temperature, TE properties of $\mathrm{CsBi}_{4} \mathrm{Te}_{6}$ doped by $0.05 \% \mathrm{SnI}_{3}$ are equivalent to old $\mathrm{Bi}_{2-\mathrm{x}} \mathrm{Sb}_{\mathrm{x}} \mathrm{Te}_{3-\mathrm{y}} \mathrm{Se}_{\mathrm{y}}$ compositions with a $\mathrm{ZT} \sim 0.8$ at $225 \mathrm{~K}$, of possible use for cooling [Chung 2000].

Strongly doped single crystals lead to higher values than ZT $\sim 0.8-0.9$ at $\sim 300 \mathrm{~K}$. The best values concern n-type $\left(\mathrm{Bi}_{0,25} \mathrm{Sb}_{0,75}\right)_{2} \mathrm{Te}_{3}$ doped with $0,07 \% \mathrm{I}$ (in mass), $0,02 \% \mathrm{Te}$, et $0,03 \% \mathrm{CuBr}$ [Yamashita 2004] leading to a $\mathrm{ZT}>1,1$ at $\sim 300 \mathrm{~K}$. For the p-type, doping by $8 \%$ in mass of Te leads to $\mathrm{ZT}=1.4$ at the same temperatures [Yamashita 2003]. The effects of Te doping as well as those of texturation induced by extrusion were previously studied in $\mathrm{Bi}_{0.5} \mathrm{Sb}_{1.5} \mathrm{Te}_{3}$ [Hong 2003]. On the con- 
trary, the addition of few percents of $\mathrm{PbTe}$ in $\mathrm{Bi}_{0,4} \mathrm{Sb}_{1,6} \mathrm{Te}_{3}$ do not lead to an improvement of ZT.

$\mathrm{K}_{2} \mathrm{Bi}_{8} \mathrm{Se}_{13}$ forms two phases : $\alpha-\mathrm{K}_{2} \mathrm{Bi}_{8} \mathrm{Se}_{13}$ (triclinic, space group $P$ - $1 \mathrm{~d}$ ) et $\beta$ $\mathrm{K}_{2} \mathrm{Bi}_{8} \mathrm{Se}_{13}$ (monoclinic, space group $P 21 / \mathrm{m}$ ). The $\beta$-phase (Fig. 6.17) has an architecture built from fragments structure type of $\mathrm{Bi}_{2} \mathrm{Te}_{3}, \mathrm{CdI}_{2}$ and $\mathrm{NaCl}$, and a mixed occupancy of the sites $\mathrm{K} / \mathrm{Bi}$ [Bilc 2005].

In $\mathrm{K}_{2} \mathrm{Bi}_{8} \mathrm{Se}_{9} \mathrm{~S}_{4}$, all the $\mathrm{S}$ sites are with a mixed occupancy and the representation (Fig. 6.17) is made according to the nature of the main occupant of the site. The thermal conductivity is very weak (complex structure, atoms vibrating in tunnels, disorder in the site occupancy) and the doping increases the Seebeck coefficient, however the ZT values are presently too small for cooling applications. Other substitutions could possibly lead to $\mathrm{p}$-type materials.

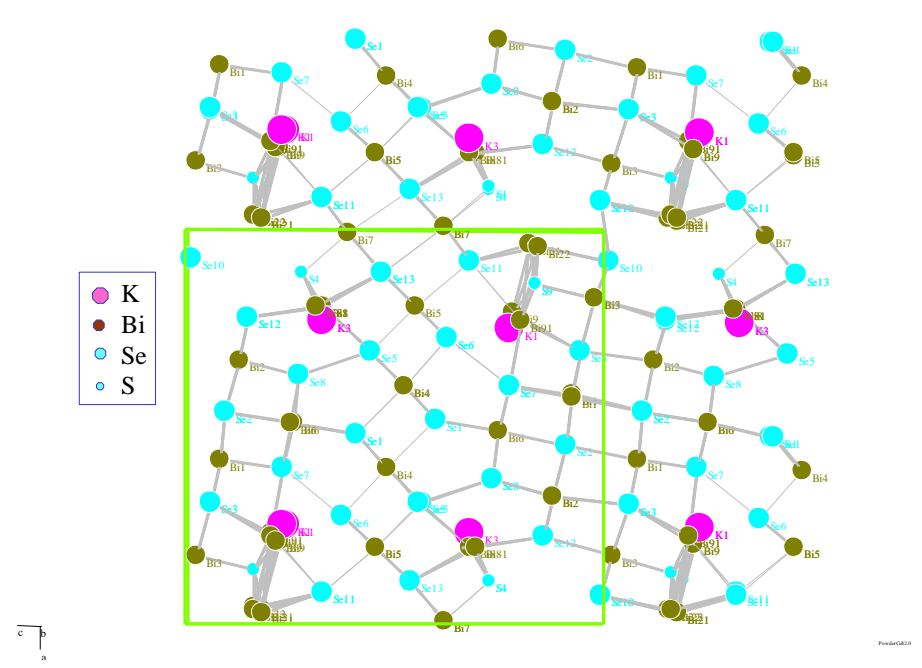

Fig. 6.17. Structure of $\mathrm{K}_{2} \mathrm{Bi}_{8} \mathrm{Se}_{9} \mathrm{~S}_{4}$

\section{4.b derivatives from $\mathrm{PbTe}$ and TAGS}

The series of cubic materials $\mathrm{AgPb}_{\mathrm{m}} \mathrm{SbTe}_{2+\mathrm{m}}$ (space group Fm3m) (Fig. 6.18) has lead to type $n$ semiconductor with high $\mathrm{ZT}$ values when $\mathrm{m}=10(\mathrm{ZT}=1$ at $700 \mathrm{~K})$ or $\mathrm{m}=18(\mathrm{ZT}=2.2$ at $800 \mathrm{~K})$ [Hsu 2004].

Smallest values of ZT have been observed in annealed Ag-deficient samples $(\mathrm{ZT}=1.1$ at $670 \mathrm{~K}$ with $\mathrm{x}=0.4$ and $\mathrm{ZT}=0.3$ with $\mathrm{x}=0.3)$. However these materials are not conventional bulk but composites (see below $\operatorname{In}_{2} \mathrm{O}_{3}+\mathrm{Ge}$ ). 


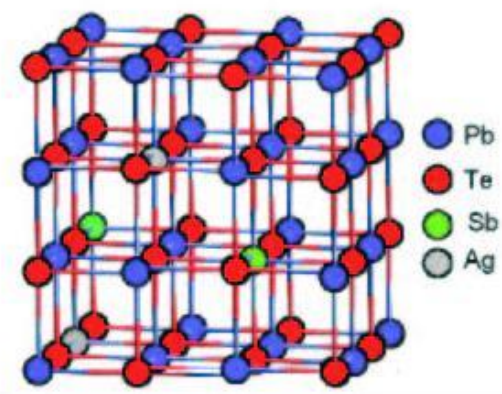

Fig. 6.18. Cubic structure of $\mathrm{AgPb}_{\mathrm{m}} \mathrm{SbTe}_{2+\mathrm{m}}$

High resolution transmission microscopy have shown that $\mathrm{Ag}-\mathrm{Sb}$ rich phase nanocrystals exist in a $\mathrm{Pb}$-Te rich matrix, that has also been described as nano-clusters of $\mathrm{AgPb}_{3} \mathrm{SbTe}_{5}$ in $\mathrm{PbTe}$ matrix [Lin 2005]. Such nano-phases could be responsible of high ZT values, theoretically predicted, and observed in quantum wells superlattice, nano-dots etc.. (see below nano-materials). The difficult control of the nature, size and dispersion of these nano-phases could be responsible of the mismatch of literature results. The effect of annealing and of eventual temperature cycling which could induce a growth of these nano-objects have not yet been checked.

\subsection{Other intermetallic compounds}

Recently, few new Sb-based compounds have been identified with good TE characteristics, a property which can be due to the property of Sb to diffuse phonons more efficiently that lighter ions with the same electronic configuration (we already mention that for skutterudites and for $\mathrm{Zn}_{4} \mathrm{Sb}_{3}$ ). Moreover, materials made from metalloid and slightly more electropositive elements (Zintl phase) seems to be able to have high ZT.

\subsection{1 $\mathrm{Yb}_{14} \mathrm{MnSb}_{11}$}

The tetragonal structure of $\mathrm{Yb}_{14} \mathrm{MnSb}_{11}$ (space group $\mathrm{I}_{1} / \mathrm{acd}$ ) is complex (Fig. 6.19) and built from various structural units. The flexibility to accommodate various elements (possibility of future improvements?) have lead to a $\mathrm{ZT}=1$ at the high temperature of $1220 \mathrm{~K}$ in this p-type material [Brown 2006]. 


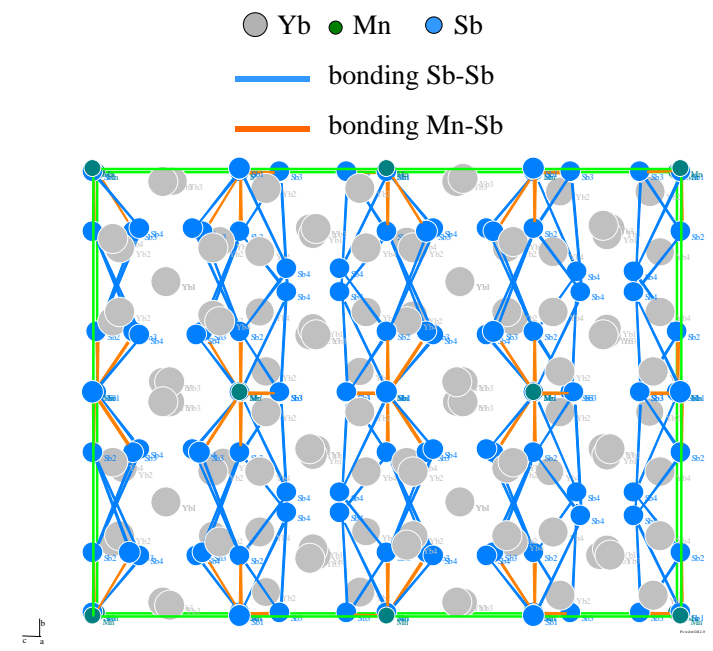

Fig. 6.19. (100) projection of the structure of $\mathrm{Yb}_{14} \mathrm{MnSb}_{11}$

\subsection{2. $\mathrm{Mo}_{3} \mathrm{Sb}_{7-\mathrm{x}} \mathrm{Te}_{\mathrm{x}}$ and derivatives}

The structure $\mathrm{Ir}_{3} \mathrm{Ge}_{7}$ (space group $\mathrm{Im} 3 \mathrm{~m}$ ) of $\mathrm{Nb}_{3} \mathrm{Te}_{7-\mathrm{x}} \mathrm{Sb}_{\mathrm{x}}$ [Wang 2002] and of $\mathrm{Mo}_{3} \mathrm{Sb}_{7-\mathrm{x}} \mathrm{Te}_{\mathrm{x}}(\mathrm{x}=1,5$ et 1,6) [Gascoin 2007] compounds forms infinite chains in the three directions of space. $\mathrm{Mo}_{3} \mathrm{Sb}_{7-\mathrm{x}} \mathrm{Te}_{\mathrm{x}}$ only exists for a VEC between 51 and 56, a value of 55 being a prerequisite to obtain a semiconductor.

With a ZT of 0.8 in $\mathrm{Mo}_{3} \mathrm{Sb}_{5,4} \mathrm{Te}_{1,6}$ at $1050 \mathrm{~K}$ [Gascoin 2007] and in $\mathrm{Mo}_{3-\mathrm{y}-\mathrm{z}} \mathrm{Ru}_{\mathrm{y}} \mathrm{Fe}_{\mathrm{z}} \mathrm{Sb}_{7}$ at $1000 \mathrm{~K}$ [Candolfi 2008] for $(\mathrm{y}, \mathrm{z})=(0.16,0.5)$ and $(0.1,0.7)$ these materials are better than the best p-type Si-Ge.

\subsubsection{Other Sb-based materials}

A ZT of 0.55 at $600 \mathrm{~K}$ was initially attributed to the phase $\mathrm{Mg}_{3} \mathrm{Sb}_{2}$ (space group $\mathrm{P} 3 \mathrm{~m} 1$ ) which was invalidated with a maximum of ZT of 0.2 at $875 \mathrm{~K}$ [Condron 2006]. Moreover, the phase looses $\mathrm{Mg}$ and oxidizes above $900 \mathrm{~K}$.

The structure of $\mathrm{CaZn}_{2} \mathrm{Sb}_{2}$ is the same than that of $\mathrm{Mg}_{3} \mathrm{Sb}_{2}$ and the material easily oxidizes. Due to its simple crystalline structure, its TE properties are poor with a ZT of 0.5 at $770 \mathrm{~K}$ [Stark 2002]. 


\subsection{4. $\mathrm{Mg}_{2} \mathrm{Si}_{1-\mathrm{x}} \mathrm{Sn}_{\mathrm{x}}$}

During the years 1960, the Ioffé Institute showed that the compounds $\mathrm{Mg}_{2} \mathrm{X}$ $(\mathrm{X}=\mathrm{Si}, \mathrm{Ge}$ or $\mathrm{Sn}$ ) are semiconductors with a band structure which should favor TE properties. Various substitutions have been tested and the best results have been obtained when the mass difference between elements is the highest, i.e., with $\mathrm{Si}$ and Sn [Fedorov 2003]. A ZT of 1.1 has then been found at $800 \mathrm{~K}$, a better value than with n-type Si-Ge [Zaitsev 2006].

\subsection{Oxides}

The main expected advantage of oxides is their chemical stability in oxidizing atmosphere, even though the stability and transport properties of some oxides depend on the partial pressure of oxygen. If many oxides have high Seebeck coefficients $(\alpha>100 \mu \mathrm{V} / \mathrm{K})$ their performance are presently limited by electrical resistivities much higher than in previously described materials.

\subsubsection{Cobaltites}

Among the most promising p-type oxides, cobaltites with conductive layers of $\mathrm{CoO}_{2}\left(\mathrm{CdI}_{2}\right.$ type $)$ have been the starting point of interest for TE oxides with $\mathrm{Na}_{\mathrm{x}-}$ $\mathrm{CoO}_{2}$ : a metallic oxide with a high Seebeck coefficient [Terasaki 1997].

\subsection{2. misfit oxides}

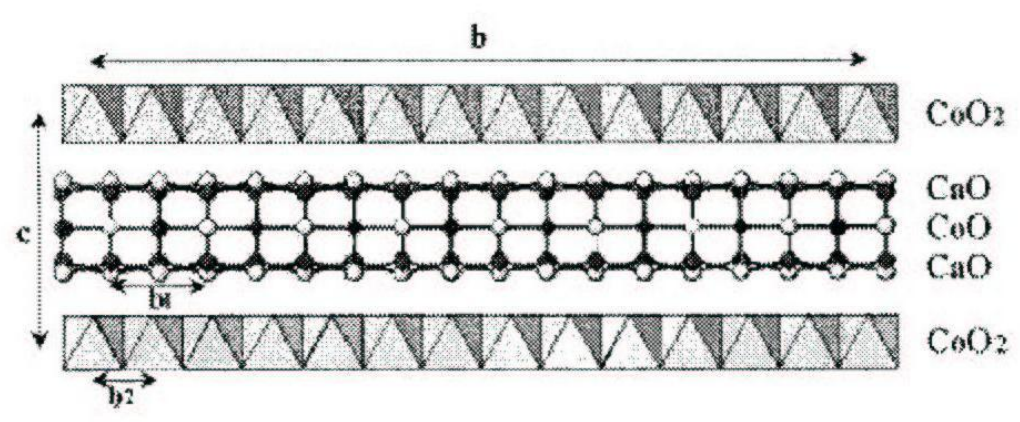

Fig. 6.20. Structure of the misfit compound $\mathrm{Ca} 3 \mathrm{Co} 4 \mathrm{O} 9(\mathrm{~b} \sim 8 \mathrm{~b} 1 \sim 13 \mathrm{~b} 2)$

Among cobaltites, the layered compound $\mathrm{Ca}_{3} \mathrm{Co}_{4} \mathrm{O}_{9}$ is in fact a lamellar oxide with misfit structure [Masset 2000] of general formulae: [AO $\left.)_{n}\right] \mathrm{RS}\left[\mathrm{CoO}_{2}\right]_{\mathrm{b} 1 / \mathrm{b} 2}$ made of $\mathrm{CoO}_{2}$ planes (as in $\mathrm{Na}_{\mathrm{x}} \mathrm{CoO}_{2}$ ) split by $\mathrm{AO}$ layers of $\mathrm{NaCl}$ type (RS: rock salt) with 
possible $n$ values of 2, 3 and 4. Considering the sub-lattice $\mathrm{CoO}_{2}$ as a mono-layer $\mathrm{NaCl}$ (quoted $\mathrm{S}_{2}$ ) which matches with the sub-lattice $\mathrm{AO}\left(\mathrm{S}_{1}\right)$ along the a-axis but mismatches along $b$-axis. The ratio of $b$-axis of $S_{1}$ and $S_{2}$, i.e., $b_{1} / b_{2}$ measures the incommensurability of the two lattices (Fig. 6.20). In the case of $\mathrm{Ca}_{3} \mathrm{Co}_{4} \mathrm{O}_{9}$, this ratio is $1.625(13 / 8)$ which leads to a formulae: $\left[\mathrm{Ca}_{2} \mathrm{CoO}_{3}\right]_{\mathrm{Rs}}\left[\mathrm{CoO}_{2}\right]_{1.62}$.

The family of lamellar oxides with misfit structure is very large (choice on $\mathrm{n}$, and A, for instance $\mathrm{Ca}, \mathrm{Bi}, \mathrm{Sr}, .$. and replacement of $\mathrm{Co}$ by $\mathrm{Rh}, . .$. ) and many new materials are conceivable, however the actual $\mathrm{ZT}$ values are low due to high electrical resistivity [Koumoto 2006].

The highest $\mathrm{ZT}$ value in an oxide has been obtained in a small size single crystal of $\mathrm{Na}_{\mathrm{x}} \mathrm{CoO}_{2}$ (estimated value of 1.2 at $800 \mathrm{~K}$ ). The impossibility to grow large enough single crystal for applications has lead to many studies concerned by texturation processes, with the drawback that the electrical conductivity in the $\mathrm{CoO}_{2}$ planes decrease as compared to crystals.

\subsection{3. other oxides}

Other oxides families have also been studied like perovskites $\mathrm{ACoO}_{3}$-type, manganites $\mathrm{AMnO}_{3}$ [Kuwahara 2004], delafossites $\mathrm{CuMO}_{2}$ [Ono 2006], YBCO $\left(\mathrm{YBa}_{2} \mathrm{Cu}_{3} \mathrm{O}_{6+\mathrm{y}}\right), \mathrm{ZnO}$ [Tanaka 1997] [Orikasa 2008], ruthenates $\mathrm{ARuO}_{3}$ [Hébert 2001] and $\mathrm{A}_{2} \mathrm{RuO}_{4}, \mathrm{In}_{2} \mathrm{O}_{3}$ etc.. The best $\mathrm{ZT}$ values reach 0.4 for the p-type and 0.3 for the n-type in conventional oxides and of 0.55 in misfits oxides.

The structure of $\operatorname{In}_{2} \mathrm{O}_{3}$ (space group Ia-3) shows alternatively ordered and disordered In-planes (see Fig. 6.21)

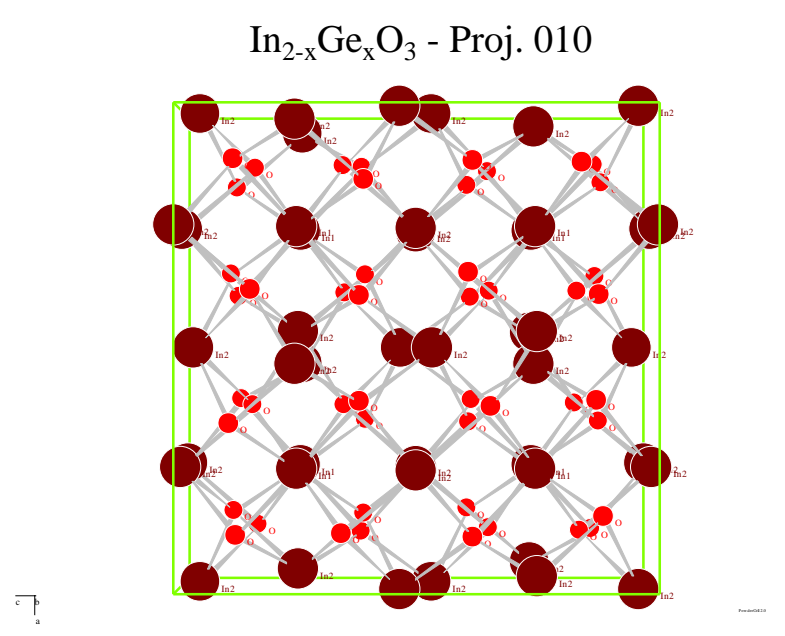

Fig. 6.21. (010) projection of $\operatorname{In}_{2} \mathrm{O}_{3}$ structure 
The solubility limit of $\mathrm{Ge}$ is no more than 0.5 atom $\%$, for higher rate of Ge the material forms a composite $\mathrm{In}_{2} \mathrm{O}_{3}+$ inclusions of micronic size $(\sim 100 \mu \mathrm{m})$ of $\mathrm{In}_{2} \mathrm{Ge}_{2} \mathrm{O}_{7}$. In that composite, the thermal conductivity is notably reduced and a ZT of 0.45 at $1243 \mathrm{~K}$ has been observed which is actually the best value for a n-type oxide.

This shows the potential of micro-composites, as well as nano-composites (see $\left.\mathrm{Ag}_{1-\mathrm{x}} \mathrm{Pb}_{18} \mathrm{SbTe}_{20}\right)$, to improve $\mathrm{ZT}$ values as compared to "parent" materials.

\section{7: ZT of new materials}

The use of the various processes, previously described, to minimize the thermal conductivity has lead to a noticeable increase of ZT from $\sim 1995$. Let us remark that the new families of materials have lead to the improvement of ZT, moreover, they have increased the temperature ranges where the TE can be used. The value of ZT in few families is higher than 1.3 (30\% increase as compared to conventional materials). The best value in a bulk material is actually of 1.7 in skutterudites. The curves of the best values of ZT versus temperature in bulk materials are shown in Fig. 6.22 and 6.23 for the p- and n-type materials, respectively.

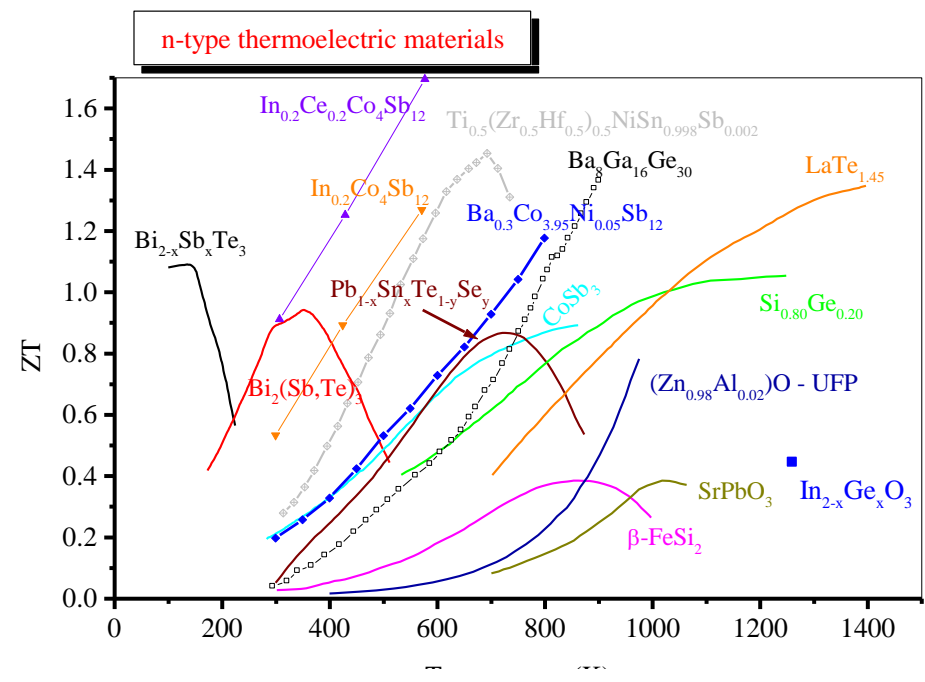

Fig. 6.22. Best $\mathrm{ZT}$ values for representatives of n-type materials 


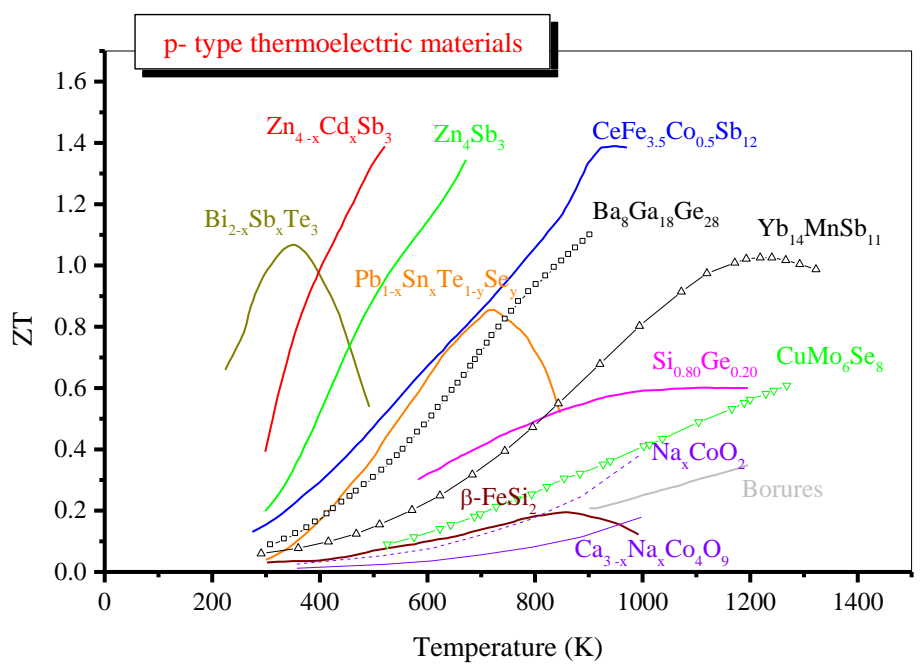

Fig. 6.23. Best ZT values for representatives of p-type materials

\subsection{Semiconducting glasses}

A certain number of characteristics leading to a weak thermal conductivity and to good TE properties, such as complex structures, inclusions, impurities, mass fluctuations, disorder, ... can be found in glass. However, glass is generally insulator except the metallic glasses which have low Seebeck coefficients (as metals). Numerous semiconducting glasses, with a small gap to favor high Seebeck coefficients, exist specially in pnictides and chalcogenides. Their preliminary studies have shown encouraging results, even though the electrical resistivity is generally too high [Gonçalves et al., in this volume] .

\section{Nano TE materials}

Transport properties in micro-, and nano- structures differ from that in bulk 3D (three-dimensional) materials. The thermal conductivity of nano-structures like super-lattices (material with periodic change of nano-metric layers of various elements or substances) is weaker than in bulk materials. This is a positive aspect for TE properties. However, these nano-structures are generally obtained by thin films techniques (Molecular Beam Epitaxy, Knudsen cells, Pulsed laser, CVD, ..) too costly to be used for the production of materials for large scale applications. Moreover, their weak thickness are not very compatible with the formation of 
large temperature gradients. Conversely, they are well adapted to micro-cooling in electronics.

Electronic transport properties are also strongly modified by dimensionality effects on the band structure (Fig. 7.1) [Dresselhaus 1999].
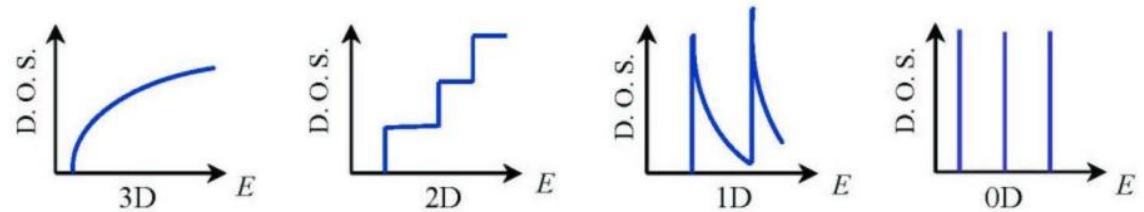

Fig. 7.1. DOS for a semiconductor $3 \mathrm{D}$, a quantum well $2 \mathrm{D}$, a nano-wire or nano-tube $1 \mathrm{D}$ and a quantum dot $0 \mathrm{D}$

To summarize, in a 3D material, $\alpha, \sigma$ and $\lambda$ are bound and it is difficult to optimize both of them, in the case of lower dimension new possibilities exist to independently adjust them.

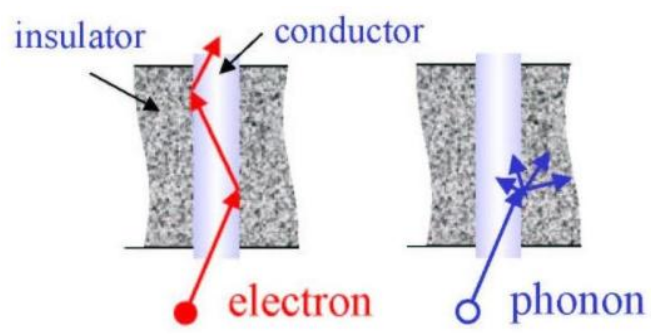

Fig. 7.2.. Proposed model for the diffusion of phonons and carriers in a 1D structure

In addition, new interfaces are created which can increase the phonon diffusion, more than that of carriers, leading to an increase value of ZT (Fig. 7.2)

It is remarkable that the improvement of ZT has been theoretically predicted [Hicks 1993] (Fig. 7.3) before its experimental observation. 


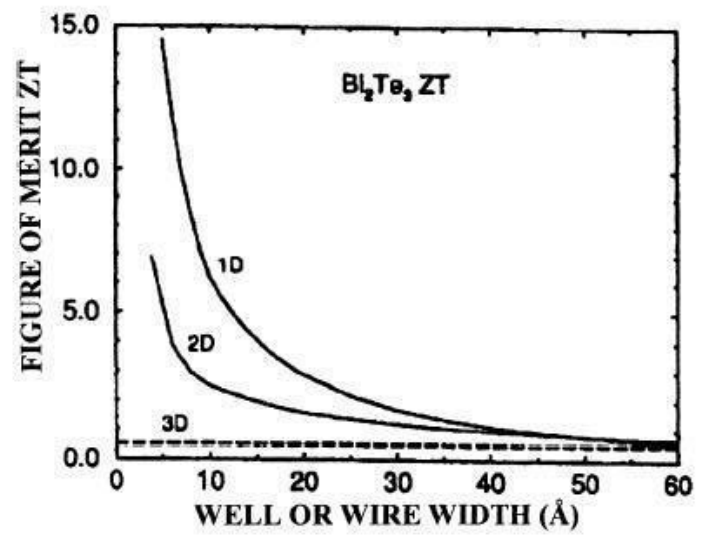

Fig. 7.3. Evolution of ZT with the dimensionality

The experimental proofs, in various forms of nano-structures, concern, for instance:

- super lattices including quantum wells PbTe-PbSeTe [Hicks 1996], in which ZT value of 1.6 has been calculated (in front of 0.4 for the bulk)

- super lattices of $\mathrm{Bi}_{2} \mathrm{Te}_{3} / \mathrm{Sb}_{2} \mathrm{Te}_{3}$, with a $\mathrm{ZT}$ of 2.4 (in front of 1.0 for the bulk) [Venkatasubramanian 2001]

- a decrease of the thermal conductivity of a Ge matrix by inclusions of Si-nanowires which depends on the diameter of the nano-wires [Yang 2005]

- an increase of the $\mathrm{ZT}$ value in various compositions of $\mathrm{Bi}_{2} \mathrm{Te}_{3}$ by addition of $\mathrm{Bi}_{2} \mathrm{Te}_{3}$-nano-powders [Ni 2005]...

These two last examples, as well as the case of $\mathrm{AgPb}_{\mathrm{m}} \mathrm{SbTe}_{2+\mathrm{m}}$ (see above) show that the study of nano-composites may allow to benefit of TE performances related to the nano-sizes with samples of large sizes ( $>$ centimeter) requested for applications. The next year should be crucial for the understanding of mechanisms in nano-composites and consequently to be able to increase beneficial effects of such systems as compared to detrimental effects, for instance, on resistivity.

\section{Shaping of nano-composites TE materials}

The shaping of such samples can be realized by hot pressing techniques. In the recent studies, this shaping is generally obtained by Spark Plasma Sintering (SPS) technique, a technique of fast sintering under pressure, which mainly avoid grain growth observed with conventional hot press. A small size SPS machine, as we acquired in CNRS Thiais (Syntex 515S), is able to perform sintering under conditions up to $50 \mathrm{MPa}$ and $2000^{\circ} \mathrm{C}$, with non costly graphite crucibles. Sample diameters of up to $20-25 \mathrm{~mm}$ are obtained for sintering temperature up to $\sim 1500^{\circ} \mathrm{C}$ for 
ceramics and $\sim 1000^{\circ} \mathrm{C}$ for intermetallics; for higher temperatures smaller diameter can be produced. These temperatures are generally sufficient as the pressure helps to sinter. Pressures of up to $500 \mathrm{MPa}$ have been realized with other crucibles (WC) at lower temperatures and diameter.

Such techniques has been used with various TE conventional powders (grains smaller than a few $10 \mu \mathrm{m}$ ) of $\mathrm{Bi}_{2} \mathrm{Te}_{3}$, skutterudites, clathrates, half Heusler, $\mathrm{Zn} 4 \mathrm{Sb} 3, \mathrm{Mg}_{2}(\mathrm{Si}, \mathrm{Sn}), \mathrm{PbTe}, \mathrm{Zno}$ derivatives, etc.. Electric contact or protection against corrosion can be made, in few cases, by direct sintering of a thin metal foil with the powder.

More recently, the technique has been successfully applied in various composites systems, the starting nano-particles being produced by sol-gel method, electrochemistry, ... but more often from ball milling:

- various compositions of $\mathrm{Bi}_{2} \mathrm{Te}_{3}$ with addition of $\mathrm{Bi}_{2} \mathrm{Te}_{3}$-nano-powders [Ni 2005]

- synthesis of $\mathrm{Yb}_{\mathrm{y}} \mathrm{Co}_{4} \mathrm{Sb}_{12} / \mathrm{Yb}_{2} \mathrm{O}_{3}$ composites [Zhao 2006]

- shaping of composite made of nano-particles of $\mathrm{SiC}$ dispersed in $\mathrm{Bi}_{2} \mathrm{Te}_{3}$ [Zhao 2008]

- shaping of binary skutterudites with $\mathrm{C}_{60}$ inclusions [Shi 2004]

- mixing of micro-nano- skutterudites [Zhang 2006]

- Bi addition in Heusler $\mathrm{V}_{2} \mathrm{FeAl}$ [Mikami 2008]

- nano-inclusions of $\mathrm{ZrO}_{2}$ in the half Heusler $\mathrm{Zr}_{0.5} \mathrm{Hf}_{0.5} \mathrm{Ni}_{0.8} \mathrm{Pd}_{0.2} \mathrm{Sn}_{0.99} \mathrm{Sb}_{0.01}$ [Chen 2006]

It is remarkable that such sintering process takes place within a short period of time (typically few minutes) and lead to density higher than $95 \%$ of the theoretical $\mathrm{X}$-ray density, a very crucial parameter for TE transport properties. This explains the increasing used of this technique for the synthesis and/or shaping of TE materials and micro-, nano-composites from 2004.

As a conclusion, within the 15 last years, bulk materials with an increased complexity (structure, solid solutions) have lead to an improvement of the TE figure of merit of $\sim 30 \%$, and sometime more, in various series. Complexity of the micro-, nano-structure seems actually promising to overtake the actual ZT values. Studies of nano-composites coupled by fast shaping process by SPS, should lead to a real potential of using thermoelectricity for large scale applications.

Acknowledgments This work was supported by the bi-lateral French-Portuguese GRICES 20072008 program and European COST P16 program. One of us (CG) acknowledges NATO support to his participation to ARW Workshop "Properties and Applications of Thermoelectric Materials" September 20 - 26, 2008 - Hvar, Croatia 


\section{References}

Abeles B.: Lattice thermal conductivity of disordered semiconductor alloys at high temperature Phys. Rev. 131, 1906 (1963)

Anno H., Nagamoto Y., Ashida K., et al.: Effect of $\mathrm{Yb}$ filling on thermoelectric properties of Co1-xMxSb3 ( $\mathrm{M}=\mathrm{Pd}, \mathrm{Pt})$ skutterudites -19th International Conference on Thermoelectrics20-24 August- Cardiff- Wales, UK p.90 (2000)

Anno, H., Nagao, J. and Matsubara, K.: Electronic and thermoelectric properties of YbyFe4xNixSb12 -21st International Conference on Thermoelectrics- Long Beach, California, USA Aug. 25-29 p. 56 (2002)

Anno H., Hokazono M., Kawamura M., et al.: Thermoelectric properties of Ba8GaxGe46-x clathrate compounds -21st International Conference on Thermoelectrics- Long Beach, California, USA - Aug. 25-29 p.77 (2002)

Bentien A., Paschen S., Pachero V., et al.: High temperature thermoelectric properties of alpha and beta-Eu8Ga16Ge30 -22nd International Conference on Thermoelectrics ICT2003, La Grand Motte, France, August p.131 (2003)

Bérardan D., Godart C., Alleno E., et al.: Chemical properties and thermopower of the new series of skutterudite $\mathrm{Ce}_{1-\mathrm{p}} \mathrm{Yb}_{\mathrm{p}} \mathrm{Fe}_{4} \mathrm{Sb}_{12}-\mathrm{J}$. Alloys Compd. 351, 18-23 (2003)

Bérardan D., Alleno E., Godart C., et al.: Improved thermoelectric properties in the double filled $(\mathrm{Ce}, \mathrm{Yb})_{\mathrm{y}}(\mathrm{Fe}, \mathrm{Co}, \mathrm{Ni})_{4} \mathrm{Sb}_{12}$ skutterudites -J. Appl. Phys. 98, 033710 (2005)

Bérardan D., Alleno E., Godart C., et al.: Synthesis of nanocrystalline filled skutterudites by mechanical alloying -24th International Conference on Thermoelectrics ICT2006,- Vienna, Austria- 6-10 Aug. p.151 (2006)

Berger S., Paul C., Bauer E., et al.: Physical properties of novel thermoelectric skutterudites EuyFe4-xCoxSb12 and EuyFe4-xNixSb12 -20th International Conference on Thermoelectrics- 8-11 june - Beijing- China p.77 (2001)

Bilc D. I., Mahanti S. D. and Kanatzidis M. G.: Electronic transport properties of $\mathrm{PbTe}$ and AgPbmSbTe2+m systems -Phys. Rev. B 74, 125202 (2006)

Blake N. P., Bryan J. D., Latturner S., et al.: Structure and stability of the clathrates Ba8Ga16Ge30, Sr8Ga16Ge30, Ba8Ga16Si30, and Ba8In16Sn30 -J. Chem. Phys. 114, 10063 (2001)

Brown S. R., Kauzlarich S. M., Gascoin F., et al.: Yb14MnSb11: New High Efficiency Thermoelectric Material for Power Generation -Chem. Mater. 18, 1873 (2006)

Caillat, T., Fleurial, J. P. and Borshchevsky, A.: Preparation and thermoelectric properties of semiconducting Zn4Sb3 -J. Phys. Chem. Solids 58, 1119 (1997)

Caillat, T., Fleurial, J. P. and Snyder, G. J.: Potential of Chevrel phases for thermoelectric applications -Solid State Sciences 1, 535-544 (1999)

Caillat, T., Borshchevsky, A. and Fleurial, J. P.: High performance thermoelectric materials based on beta Zn4Sb3 -Report NPO19851- JPL, Pasadena, USA (1999a)

Caillat T., Kisor A., Lara L., et al.: Progress Status of Skutterudite-Based Segmented Thermoelectric Technology Development -23rd International Conference on Thermoelectrics- Adelaide, Australia 25 - 29 July 2004 (2004)

Callaway, J. and von Baeyer, H. C.: Effect of point imperfections on lattice thermal conductivity -Phys. Rev. 120, 1149 (1960)

Candolfi, C.: Synthèse, caractérisation physico-chimique et propriétés de transport de composés de type Mo3Sb7 -Thesis University of Nancy, France- 6 Oct. (2008)

Chakoumakos B. C., Sales B. C., Mandrus D., et al.: Disparate atomic displacements in skutterudite type LaFe3CoSb12, a model for thermoelectric behaviour -Acta Crystallogr. 55, 341 (1999) 
Chakoumakos, B. C., Mandrus, D. and Sales, B. C.: Structural disorder and magnetism of the semiconducting clathrate Eu8Ga16Ge30 -J. Alloys Compd. 322, 127 (2000)

Chen B., Xu J. H., Uher C., et al.: Low temperature transport properties of the filled skutterudites CeFe4-xCoxSb12 -Phys. Rev. B 55, 1476 (1997)

Chen L. D., Kawahara T., Tang X. F., et al.: Anomalous barium filling fraction and n-type thermoelectric performance of BayCo4Sb12 -J. Appl. Phys. 90, 1864 (2001)

Chen L. D., Huang X. Y., Zhou M., et al.: The high temperature thermoelectric performances of

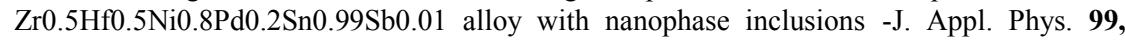
$064305(2006)$

Chung D. Y., Hogan T. P., Brazis P., et al.: CsBi4Te6: a high performance thermoelectric material for low temperature applications -Science 287, 1024 (2000)

Condron C. L., Kauzlarich S. M., Gascoin F., et al.: Thermoelectric properties and microstructure of Mg3Sb2 -J. Solid State Chem. 179, 2252 (2006)

Deng S., Tang X., Li P., et al.: High temperature thermoelectric transport properties of p-type Ba8Ga16AlxGe30-x type-I clathrates with high performance -J. Appl. Phys. 103, 073503 (2008)

Dresselhaus M. S., Dresselhaus G., Sun X., et al.: Low-dimensional thermoelectric materials Phys. Solid State 41, 679 (1999)

Dyck J. S., Chen W., Uher C., et al.: Thermoelectric properties of the n-type filled skutterudite Ba0.3Co4Sb12 -J. Appl. Phys. 91, 3698 (2002)

Fedorov M. I., Pshenaj-Severin D. A., Zaitsev V. K., et al.: Features of conduction mechanism in n-type Mg2Sil-xSnx solid solutions -22nd International Conference on Thermoelectrics ICT2003, La Grand Motte, France, August p.142 (2003)

Fleurial J. P., Borshchevsky A., Caillat T., et al.: High figure of merit in Ce filled skutterudites 15th International Conference on Thermoelectrics. 26-29 March 1996 Pasadena, CA, USA p.91-95 (1996)

Fleurial, J. P., Caillat, T. and Borshchevsky, A.: Skutterudites: an update -16th International Conference on Thermoelectrics. 26-29 Aug. 1997 Dresden, Germany p.1-11 (1997)

Gascoin, F., Rasmussen, J. and Snyder, G. J.: High temperature thermoelectric properties of Mo3Sb7-xTex x=1.6 and 1.5 -J. Alloys Compd. 427, 324 (2007)

Gougeon, P., Potel, M. and Gautier, R.: Syntheses and Structural, Physical, and Theoretical Studies of the Novel Isostructural Mo9 Cluster Compounds Ag2.6CsMo9Se11, Ag4.1ClMo9Se11, and h-Mo9Se11 with Tunnel Structures -Inorg. Chem. 43, 1257 (2004)

Grin, Y.N.: Chemistry and physics of intermetallic clathrates -14th International Conference on Solids Compounds of Transition Elements, Linz, Austria - 6-11 July (2003)

He, T., Krajewski, J. J. and Subramanian, M. A.: High performance thermoelectric materials and their method of preparation -US Patent - US 2005/0229963 A1 (2005)

He T., Chen J., Rosenfeld H. D., et al.: Thermoelectric properties of indium filled skutterudites Chem. Mater. 18, 759 (2006)

Hébert S., Flahaut D., Pelloquin D., et al.: Cobalt oxides as potential thermoelectric elements: the influence of the dimensionality -22nd International Conference on Thermoelectrics ICT2003, La Grand Motte, France, August p.161 (2003)

Hicks L. D. and Dresselhaus M. S.: Thermoelectric figure of merit of a one-dimensional conductor -Phys. Rev. B 47, 16631 (1993)

Hicks L. D., Harman T. C., Sun X., et al.: Experimental study of the effect of quantum-well structures on the thermoelectric figure of merit -Phys. Rev. B 53, R10493 (1996)

Hong, S. J. and Chun, B. S.: Microstructure and thermoelectric properties of extruded n-type (Bi2Te3-Bi2Se3) alloy along bar length -Mater. Sci. Eng., A 356, 345 (2003)

Hsu K. F., Loo S. L., Guo F., W., et al.: Cubic AgPbmSbTe2+m: bulk thermoelectric materials with high figure of merit -Science 303, 818 (2004)

Jeitschko, W. and Braun, D. J.: LaFe4P12 with filled CoAs type structure and isotypic LnxMyPz. -Acta Crystallogr. 33, 3401 (1977) 
Jodin L., Tobola J., Pecheur P., et al.: Effect of substitutions and defects in half-Heusler FeVSb studied by electron transport measurements and KKR-CPA electronic structure calculations Phys. Rev. B 70, 184207 (2004)

Kaspar, J. S., et al.: Intermetallic clathrates -Science 150, 1713 (1965)

Katsuyama S., Schichijo Y., Ito M., et al.: Thermoelectric properties of the skutterudite Co1xFexSb3 system -J. Appl. Phys. 84, 6708 (1998)

Katsuyama S., Kanayama T., Ito M., et al.: Thermoelectric properties of CoSb3 with dispersed FeSb2 particles -J. Appl. Phys. 88, 3484 (2000)

Katsuyama S., Watanabe M., Kuroki M., et al.: Effect of NiSb on the thermoelectric properties of skutterudite CoSb3 -J. Appl. Phys. 93, 2758 (2003)

Klemens, P. G.: Thermal resistance due to point defects at high temperature -Phys. Rev. 119, 507 (1960)

Koumoto, K., Terasaki, I. and Funahashi, R.: Complex oxide materials for potential thermoelectric applications -MRS Bull. 31, 206 (2006)

Kurosaki K., Kosuga A., Muta H., et al.: Ag9T1Te5: a high performance thermoelectric bulk material with extremely low thermal conductivity -Appl. Phys. Lett. 87, 061919 (2005)

Kuwahara H., Hirobe Y., Nagayama J., et al.: Thermoelectric properties of filling controlled manganites -J. Magn. Magn. Mater. 272-276, e1393 (2004)

Kuznetsov V. L., Kuznetsova L. A. and Rowe D. M.: Effect of partial void filling on the transport properties of NdxCo4Sb12 skutterudites -J. Phys.: Condens. Matter 15, 5035 (2003)

Lamberton G. A., Bhattacharya S., Littleton R. T., et al.: High figure of merit in Eu filled CoSb3 based skutterudites -Appl. Phys. Lett. 80, 598 (2002)

Leithe-Jasper A., Schnelle W., Rosner H., et al.: Ferromagnetic Ordering in Alkali-Metal Iron Antimonides: NaFe4Sb12 and KFe4Sb12 -Phys. Rev. Lett. 91, 037208 (2003)

Lin H., Bozin E. S., Billinge S. J. L., et al.: Nanoscale clusters in the high performance thermoelectric AgPbmSbTem+2 -Phys. Rev. B 72, 174113 (2005)

Masset A. C., Michel C., Maignan A., et al.: Misfit-layered cobaltite with an anisotropic giant magnetoresistance: Ca3Co4O9 -Phys. Rev. B 62, 166 (2000)

Mastronardi K., Young D., Wang C. C., et al.: Antimonides with the half-Heusler structure: New thermoelectric materials -Appl. Phys. Lett. 74, 1415 (1999)

McGuire M. A., Schmidt A. M., Gascoin F., et al.: Thermoelectric and structural properties of a new Chevrel phase: Ti0.3Mo5RuSe8 -J. Solid State Chem. (2006)

Mikami M. and Kobayashi K.: Effect of Bi addition on microstructure and thermoelectric properties of Heusler Fe2VAl sintered alloy -J. Alloys Compd. 466, 530-534 (2008)

Mudryk Y., Rogl P., Paul C., et al.: Thermoelectricity of clathrate I type Si- and Ge-phases -J. Phys., Condens. Matter 14, 7991-8004 (2002)

Nagamoto, Y., Tanaka, K. and Koyanagi, T.: Transport properties of heavily doped n-type CoSb3 -17th International Conference on Thermoelectrics. 24-28 May - Nagoya, Japan p.302 (1998)

Ni H. L., Zhao X. B., Zhu T. J., et al.: Synthesis and thermoelectric properties of Bi2Te3 based nanocomposites -J. Alloys Compd. 397, 317 (2005)

Nolas, G. S., Cohn, J. L. and Slack, G. A.: Effect of partial voigt filling on the lattice thermal conductivity of skutterudites -Phys. Rev. B 58, 164 (1998)

Nolas G. S., Cohn J. L., Slack G. A., et al.: Semiconducting Ge clathrates: promising for thermoelectric applications -Appl. Phys. Lett. 73, 178 (1998)

Nolas G. S., Kaeser M., Littleton R. T., et al.: Partially filled skutterudites- optimizing the thermoelectric properties -MRS Spring Meeting, Boston, Massachusetts, US- April 626, p.Z10.1.1 (2000)

Oestreich J., Probst U., Richardt F., et al.: Thermoelectric properties of the compounds ScMSb and YMSb (M=Ni, Pd, Pt) -J. Phys., Condens. Matter 15, 635 (2003)

Ono Y., Satoh K., Nozaki T., et al.: Structural, magnetic and thermoelectric properties of Delafossite type oxide $\mathrm{CuCr1}-\mathrm{xMgxO} 2$-24th International Conference on Thermoelectrics ICT2006,- Vienna, Austria- 6-10 Aug., ***, (2006) 
Orikasa Y., Hayashi N. and Muranaka S.: Effects of oxygen gas pressure on structural, electrical, and thermoelectric properties of $(\mathrm{ZnO}) 3 \mathrm{In} 2 \mathrm{O} 3$ thin films deposited by rf magnetron sputtering -J. Appl. Phys. 103, 113703 (2008)

Peltier, J. C.: Mémoire sur la formation des tables des rapports qu'il y a entre la force d'un courant électrique et la déviation des aiguilles des multiplicateurs; suivi de recherches sur les causes de pertubation des couples thermo-électriques et sur les moyens de s'en garantir dans leur emploi a la mesure des températures moyennes -Ann. Chim. (Paris) 1, 371 (1834)

Potel M., Gougeon P., Merdrignac-Conanec O., et al.: -Meeting of the French GDR "Thermoélectricité" - Juillet, Paris (2008)

Puyet M., Dauscher A., Lenoir B., et al.: Beneficial effect of Ni substitution on the thermoelectric properties in partially filled CayCo4-xNixSb12 skutterudites -J. Appl. Phys. 97, 083712 (2005)

Sales, B. C., Mandrus, D. and Williams, R. K.: Filled skutterudite antimonides: a new class of thermoelectric materials -Science 272, 1325 (1996)

Sales B. C., Mandrus D., Chakoumakos B. C., et al.: Filled skutterudite antimonides: electron crystals and phonon glasses -Phys. Rev. B 56, 15081 (1997)

Sales B. C., Chakoumakos B. C., Mandrus D., et al.: Atomic displacement parameters and the lattice thermal conductivity of clathrate like thermoelectric compounds -J. Solid State Chem. 146, 528 (1999)

Sales, B. C., Chakoumakos, B. C. and Mandrus, D.: Thermoelectric properties of thallium filled skutterudites -Phys. Rev. B 61, 2475 (2000)

Sales, B. C., Chakoumakos, B. C. and Mandrus, D.: Connections between crystallographic data and new thermoelectric compounds -MRS 626, p.Z7.1.1 (2000)

Schmidt A. M., McGuire M. A., Gascoin F., et al: Synthesis and thermoelectric properties of $\left(\mathrm{Cu}_{\mathrm{y}} \mathrm{Mo}_{6} \mathrm{Se}_{8}\right)_{1-\mathrm{x}}\left(\mathrm{Mo}_{4} \mathrm{Ru}_{2} \mathrm{Se}_{8}\right)_{\mathrm{x}}\left(\mathrm{Cu}_{\mathrm{y}} \mathrm{Mo}_{6} \mathrm{Se}_{8}\right)_{1-\mathrm{x}}\left(\mathrm{Mo}_{4} \mathrm{Ru}_{2} \mathrm{Se}_{8}\right)_{\mathrm{x}}$ alloys $-\mathrm{J}$. Alloys Compd. 431, 262 (2007)

Schweika W., Hermann R. P., Prager M., et al.: Dumbbell Rattling in Thermoelectric Zinc Antimony -Phys. Rev. Lett. 99, 125501 (2007)

Seebeck, T. J.: Magnetisch polarisation der metalle und erze durch temperatur differenz -Abh. Akad. Wiss. Berlin 1820-1821 289-346 (1822)

Sharp J. W., Sales B. C., Mandrus D., et al.: Thermoelectric properties of T12SnTe5 and T12GeTe5 -Appl. Phys. Lett. 74, 3794 (1999)

Shi X., Chen L., Yang J., et al.: Enhanced thermoelectric figure of merit of CoSb3 via large defect scattering -Appl. Phys. Lett. 84, 2301 (2004)

Shutoh, N. and Sakurada, S.: Thermoelectric properties of Tix $(\mathrm{Zr}, \mathrm{Hf}) 1-\mathrm{xNiSn}$ half Heusler compounds -22nd International Conference on Thermoelectrics ICT2003, La Grand Motte, France, August p.312 (2003)

Slack, G. A. and Tsoukala, V. G.: Some properties of semiconducting IrSb3 -J. Appl. Phys. 76, $1665(1994)$

Slack G.A., Thermoelectric Handbook- Ed. Rowe D.M.- Chemical Rubber, Boca Raton FL, (1995), p. 407

Snyder G. J., Christensen M., Nishibori E., et al.: Disordered zinc in Zn4Sb3 with phonon-glass and electron-crystal thermoelectric properties -Nature Materials 3, 458 (2004)

Stark, D. and Snyder, G. J.: The synthesis of CaZn2Sb2 and its thermoelectric properties $-21 \mathrm{st}$ International Conference on Thermoelectrics- Long Beach, California, USA - Aug. 25-29 p.181 (2002)

Tanaka Y., Ifuku T., Tsuchida K., et al.: Thermoelectric properties of $\mathrm{ZnO}$ based materials -J. Mater. Sci. Lett. 16, 155 (1997)

Terasaki, I., Sasago, Y. and Uchinokura, K.: Large thermoelectric power in NaCo2O4 single crystals -Phys. Rev. B 56, 12685 (1997)

Thompson, W.: On the dynamical theory of heat Part VI.Thermoelectric Currents. -Proceedings of the Royal Society of Edinburgh 91, (1851)

Venkatasubramanian R., Sivola E., Colpitts T., et al.: Thin film thermoelectric devices with high room temperature figures of merit -Nature 413, 597 (2001) 
Wang, S., Snyder, G. J. and Caillat, T.: Thermoelectric properties of Nb3SbxTe7-x -21st International Conference on Thermoelectrics- Long Beach, California, USA - Aug. 25-29 p.170 (2002)

Wojciechowski K. T., Malecki A., Leszczynski J., et al.: Physical properties of Te doped CoSb3 -6th Europ. Workshop on Thermoelectrics- 20-21 Sept.- Freiberg im Breisgau, Austria (2001)

Wolfing B., Kloc C., Teubner J., et al.: High performance thermoelectric T19BiTe6 with an extremely low thermal conductivity -Phys. Rev. Lett. 86, 4350 (2001)

Worlock J. M.: Thermal conductivity in sodium chloride containing silver colloids -Phys. Rev. 147, 636 (1966)

Yamashita, O., Tomiyoshi, S. and Makita, K.: Bismuth telluride compounds with high thermoelectric figures of merit -J. Appl. Phys. 93, 368 (2003)

Yamashita, O. and Tomiyoshi, S.: High performance n-type bismuth telluride with highly stable thermoelectric figure of merit -J. Appl. Phys. 95, 6277 (2004)

Yang, R., Chen, G. and Dresselhaus, M. S.:Thermal conductivity of simple and tubular nanowire composites in the longitudinal direction -Phys. Rev. B 72, 125418 (2005)

Zaitsev V.K., Fedorov M. I., Gurieva E. A., et al.: Highly effective Mg2Si1-xSnx thermoelectrics -Phys. Rev. B 74, 045207 (2006)

Zhao X.Y., Shi X., Chen L. D., et al.: Synthesis of YbyCo4Sb12/Yb2O3 composites and their thermoelectric properties -Appl. Phys. Lett. 89, 092121 (2006)

Zhao L.D., Zhang B.P., Li J.F., et al.: Thermoelectric and mechanical properties of nano-SiCdispersed $\mathrm{Bi} 2 \mathrm{Te} 3$ fabricated by mechanical alloying and spark plasma sintering -J. Alloys Compd. 455, 259 (2008) 